\title{
Thrombospondin-1 might be a therapeutic target to suppress RB cells by regulating the DNA double-strand breaks repair
}

\author{
Pei Chen ${ }^{1, *}$, Na Yu ${ }^{1, *}$, Zhang Zhang ${ }^{1}$, Ping Zhang ${ }^{1}, Y_{i n g}$ Yang $^{1}$, Nandan $\mathbf{W u}^{1}$, \\ Lijun $X u^{1}$, Jing Zhang ${ }^{1}$, Jian $\mathbf{G e}^{1}$, Keming $\mathbf{Y u}^{1}{ }^{1}$, Jing Zhuang ${ }^{1}$ \\ ${ }^{1}$ State Key Laboratory of Ophthalmology, Zhongshan Ophthalmic Center, Sun Yat-sen University, P. R. China 510060 \\ *These authors have contributed equally to this work \\ Correspondence to: Jing Zhuang, e-mail: zhuangj@mail.sysu.edu.cn
}

Keywords: DNA double strand breaks, histone deacetylation, retinoblastoma, Thrombospondin- 1

Received: June 08, 2015

Accepted: December 29, 2015

Published: January 07, 2016

\section{ABSTRACT}

\begin{abstract}
Retinoblastoma (RB) arises from the retina, and its growth usually occurs under the retina and toward the vitreous. Ideal therapy should aim to inhibit the tumor and protect neural cells, increasing the patient's life span and quality of life. Previous studies have demonstrated that Thrombospondin-1 (TSP-1) is associated with neurogenesis, neovascularization and tumorigenesis. However, at present, the bioactivity of TSP-1 in retinoblastoma has not been defined. Herein, we demonstrated that TSP-1 was silenced in RB cell lines and clinical tumor samples. HDAC inhibitor, Trichostatin A (TSA), could notably transcriptionally up-regulate TSP-1 in RB cells, WERI-Rb1 cells and Y79 cells. Moreover, we found human recombinant TSP-1 (hTSP-1) could significantly inhibit the cell viability of RB cells both in vitro and in vivo. Interestingly, hTSP-1 could significantly induce the expression of $\mathrm{Y}-\mathrm{H} 2 \mathrm{AX}$, a well-characterized in situ marker of DNA double-strand breaks (DSBs) in RB cells. The DNA NHEJ pathway in WERI-Rb1 cells could be significantly inhibited by hTSP-1. A mutation in Rb1 might be involved in the hTSP-1-medicated $\gamma$-H2AX increasing in WERI-Rb1 cells. Furthermore, hTSP-1 could inhibit RB cells while promoting retinal neurocyte survival in the neuronal and retinoblastoma cell co-culture system. As such, TSP-1 may become a therapeutic target for treatment of retinoblastoma.
\end{abstract}

\section{INTRODUCTION}

Retinoblastoma is a pediatric eye tumor arising in the retina, representing the most common childhood intraocular malignancy. Despite a good understanding of its etiology, mortality from retinoblastoma is approximately $70 \%$ in countries of low and middle income. Worldwide, most of the estimated 9000 newly diagnosed patients every year will unfortunately die [1]. Currently, several treatments are available for retinoblastoma, including chemotherapy, radioactive plaque, external beam radiotherapy, cryotherapy and surgery [2]. However, each of these therapies has major drawbacks for pediatric patients. Ideal therapeutic agents for the treatment of tumors should possess the following properties: inhibition of the proliferation of tumor cells and protection of neurons against the excitotoxicity induced by retinoblastoma cells. New adjuvant treatments with better safety and efficacy profiles are needed for retinoblastoma.
TSP-1, a matricellular protein, plays multiple roles in tumor development $[3,4]$. It is clear that TSP-1 is involved in inhibiting angiogenesis both in vitro and in vivo [4-5]. However, the expression level of TSP-1 is different in divergent types of tumors. For example, TSP-1 is highly expressed in the cells of thyroid cancer, breast and colon cancer, and glioma [6-9]. In contrast, TSP-1 is silenced in a subset of undifferentiated, advanced-stage tumors and neuroblastoma cell lines [10]. Currently, the expression level of TSP-1 in retinoblastoma remains unclear, although some studies have indicated that TSP-1 is present in the intraocular fluids and drainage pathway, where it might function in maintaining the anti-angiogenic environment and in intraocular pressure control, respectively [11].

Moreover, the role of TSP-1, which has been identified either as a tumor suppressor or as a tumor promoter, in cancer progression remains controversial [4]. Some studies have demonstrated that TSP-1 promotes tumor growth by enhancing cell migration, invasion and 
proliferation $[12,13]$. TSP-1 promoted tumor cell invasion and metastasis by cooperating with VEGF, FGF2, and TGF- $\beta 2[14,15]$. TSP-1 levels were higher in patients with advanced breast cancer $v s$. patients with early breast cancer [16]. Elevated secretion of TSP-1 has sometimes been considered a predictive factor in diagnosis [3]. However, multiple evidences exist indicating that TSP-1 inhibited angiogenesis by direct effects on endothelial cell migration and survival by activating CD36, caspase-3 and VEGFR-2 [17, 18]. Conflicting results have been obtained, indicating that TSP-1 could paracrinically inhibit tumor angiogenesis and suppress the growth of solid tumors by the BMP4/thrombospondin-1 loop [19]. In addition, TSP1 might be associated with DNA damage. TSP-1 could stimulate phosphorylation of $\mathrm{p} 47$ and increase production of superoxide, which induced cell death [20]. TSP-1 signaling could correspondingly increase high radiosensitivity. Conversely, soft tissues in TSP-1-null mice are remarkably resistant to radiation injury [21]. Guo's study directly demonstrated that intact TSP-1 and its active type I repeat peptides could cause DNA disability and result in notably DNA fragments in endothelial cells [22]. Moreover, one patent related to TSP-1 in cancer therapy has been approved by the U.S. FDA [23]. Knockdown of TSP-1 resulted in a reduction in the adhesion and migration/invasion of human thyroid cancer cells [6]. Currently, the bioactivity of TSP-1 in retinoblastoma has been not well defined.

Furthermore, more evidence has indicated that TSP1 plays an important role in neural development and neural protection [24]. Blake et al reported that TSP-1 promoted neural cell migration by binding to ApoER2 in postnatal neuronal migration [25]. TSP-1 astrocyte-secreted proteins could promote CNS synaptogenesis [26, 27]. TSP-1 is necessary for synaptic plasticity and functional recovery after stroke [28, 29]. Additionally, our previous study proved that TSP-1 secreted by bone marrow stromal cells could contribute to retinal ganglion cell neurite outgrowth and survival [30]. The treatment of retinoblastoma by surgery or other procedures often causes damage to the neurocytes of the retina. Therefore, determining the bioactivity of TSP-1 in retinoblastoma might be helpful not only for tumor therapy but also for retinal protection.

Based on the evidence above, we sought to determine the expression profile and bioactivity of TSP-1 in retinoblastoma cells both in vitro and in vivo conditions, and examined the possible underlying mechanisms of TSP-1-mediated anti-retinoblastoma action.

\section{RESULTS}

\section{TSP-1 is silenced in clinical RB tumor samples and $R B$ cells and histone deacetylation might be involved in this process}

We first measured the expression level of TSP1 in 14 RB tumor samples diagnosed and verified by oncologists. A lobular type of human breast cancer tissue sample was used as a positive control. Our results showed that TSP-1 was silenced in the human retinoblastoma, whereas it was expressed in the human breast cancer (Figure 1A). Moreover, we measured TSP-1 expression level in other 3 samples and WERI-Rb1 cells by RT-PCR and western blot. As shown in Figure 1B, TSP-1 was absent in the three clinical RB samples (Line1-3) and WERI-Rb1 cells (Line 4), compared to Hela cells (Line 5).

Epigenetic mechanisms have been shown to be responsible for the silencing of TSP-1 in a variety of human cancers $[10,31]$. Thus, to examine the role of DNA demethylation and histone deacetylase activity played in the silencing of the TSP-1 gene, WERI-Rb1 cells were treated with the demethylating agent 5-Aza$\mathrm{dC}$ and the histone deacetylase inhibitor TSA, alone or in combination. Our results showed that TSP-1 was notably induced by TSA (500 nM) in WERI-Rb1 cells, whereas treatment with 5 -Aza-dC $(5 \mu \mathrm{M})$ had no effect on TSP-1 expression (Figure 1C). As shown in Figure 1D, TSP-1 was induced by TSA in a dose-dependent manner. WERIRb1 cells treated with $250 \mathrm{nM}$ TSA markedly expressed TSP-1, compared to the controls by RT-PCR assay. To further validate the expression level of TSP-1 in the retinoblastoma cells, we analyzed its expression level in two kinds of RB cell lines, WERI-Rb1 and Y79. Realtime RT-PCR assay indicated the mRNA level of TSP-1 was barely detectable in both WERI-Rb1 and Y79 cells, however, significantly up-regulated upon 250 nM TSA treatment for 48 hours (Figure 1E). Moreover, TSA has shown stronger effect in inducing the expression of TSP1 on Y79 cells (by 3.25 -fold) than on WERI-Rb1 cells (by 1.18 -fold) $(* \mathrm{p}<0.05)$. Furthermore, western blot and immunohistofluorescence assay also demonstrated that the expression level of TSP-1 in both WERI-Rb1 and Y79 cells was time-dependently increased after treatment with TSA (Figure $1 \mathrm{~F}$ and $1 \mathrm{G}$ ).

Moreover, we examined acetylated histone $\mathrm{H} 3$, as well as total histone $\mathrm{H} 3$ levels, to demonstrate that the inhibition of histone deacetylase by TSA resulted in a global increase in histone acetylation. Western blot was performed to assay the expression of acetylated histone H3, acetylated at Lys14, 27, 56 and K18, in WERIRb1 cells after treatment with $250 \mathrm{nM}$ TSA at different time points. As shown in Figure 2A, the basal levels of acetylated histone were quite low in the control cells, compared to the expression of histone H3. Acetylated histone H3, at Lys14, 27, 56 and K18, was dramatically increased at $6 \mathrm{~h}$ and $12 \mathrm{~h}$ and then decreased to basal levels at $24 \mathrm{~h}$ in TSA-treated WERI-Rb1 cells, compared to the untreated cells. To determine which HDAC isoform was responsible for the induction of TSP-1 gene expression, we also examined the effects of treatment with the HDAC inhibitor TSA on the expression of the various HDAC genes by RT-PCR assay. As shown in Figure 2B, TSA remarkably reduced the expression levels of HDAC4 
and HDAC8. Except for the expression changes in HDAC4 and HDAC8, the expression of the other HDAC genes was not altered to a significant extent (data not shown). Western blot assay also confirmed this outcome (Figure 2C).
To further define that histone deacetylation is involved in TSP-1 silencing, WERI-Rb1 cells transfected with the construct, which contains human TSP-1 promoter sequences from -2033 to +750 and a chloramphenicol acetyltransferase (CAT)-encoding reporter gene, were
A
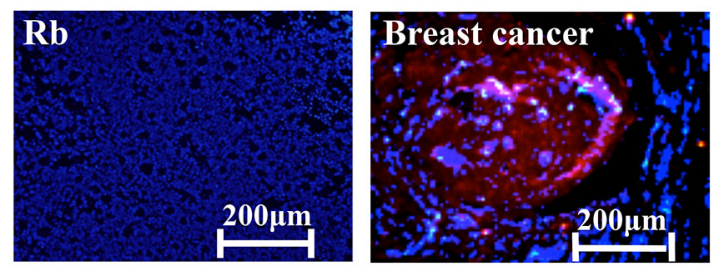

C

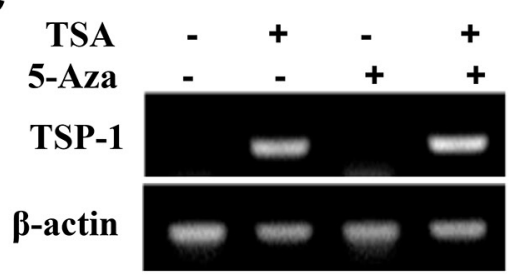

$\mathbf{F}$
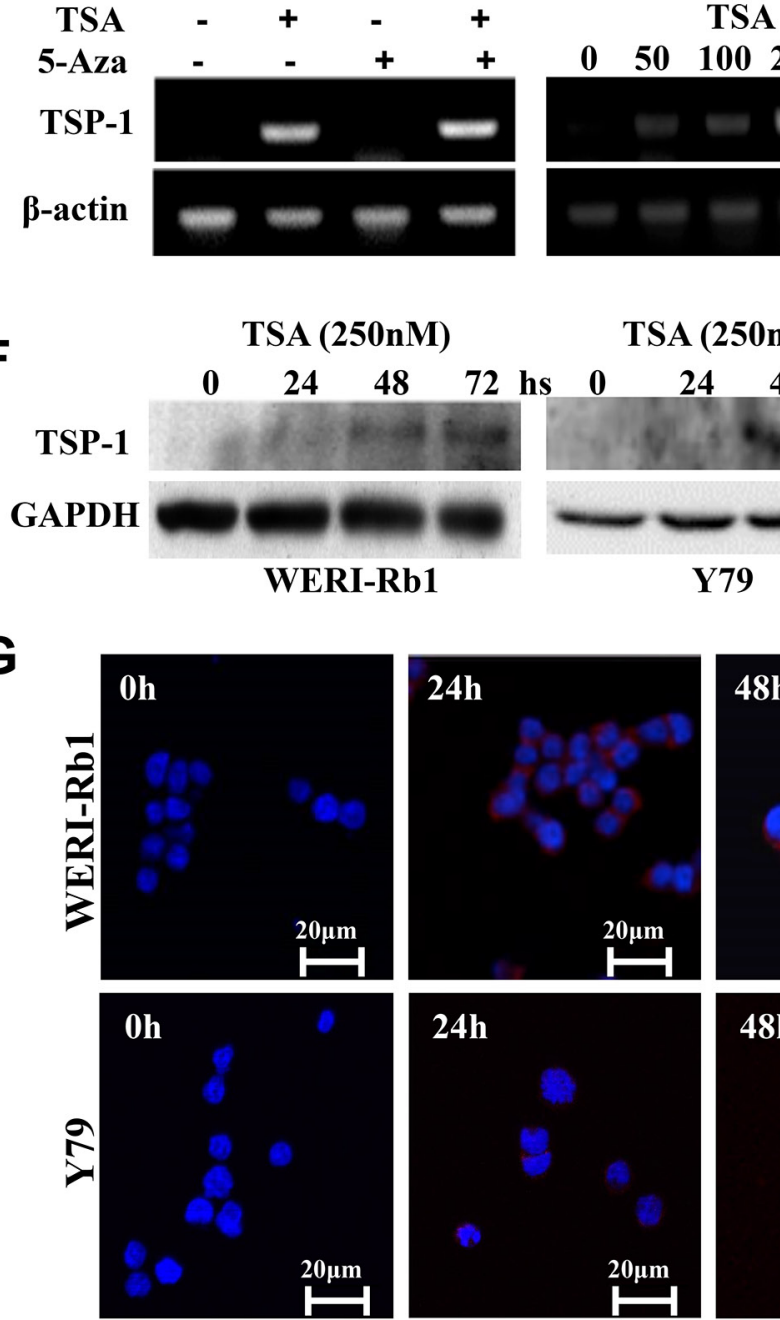

Y79
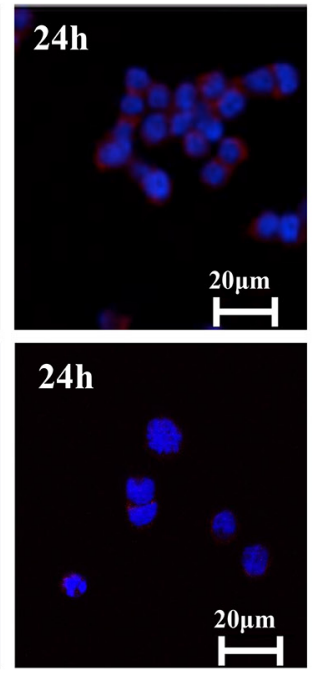

D

$\begin{array}{llllll}0 & 50 & 100 & 250 & 500 & (\mathrm{nM})\end{array}$
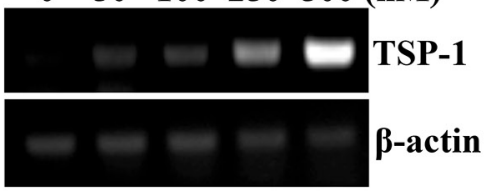

TSA (250nM)
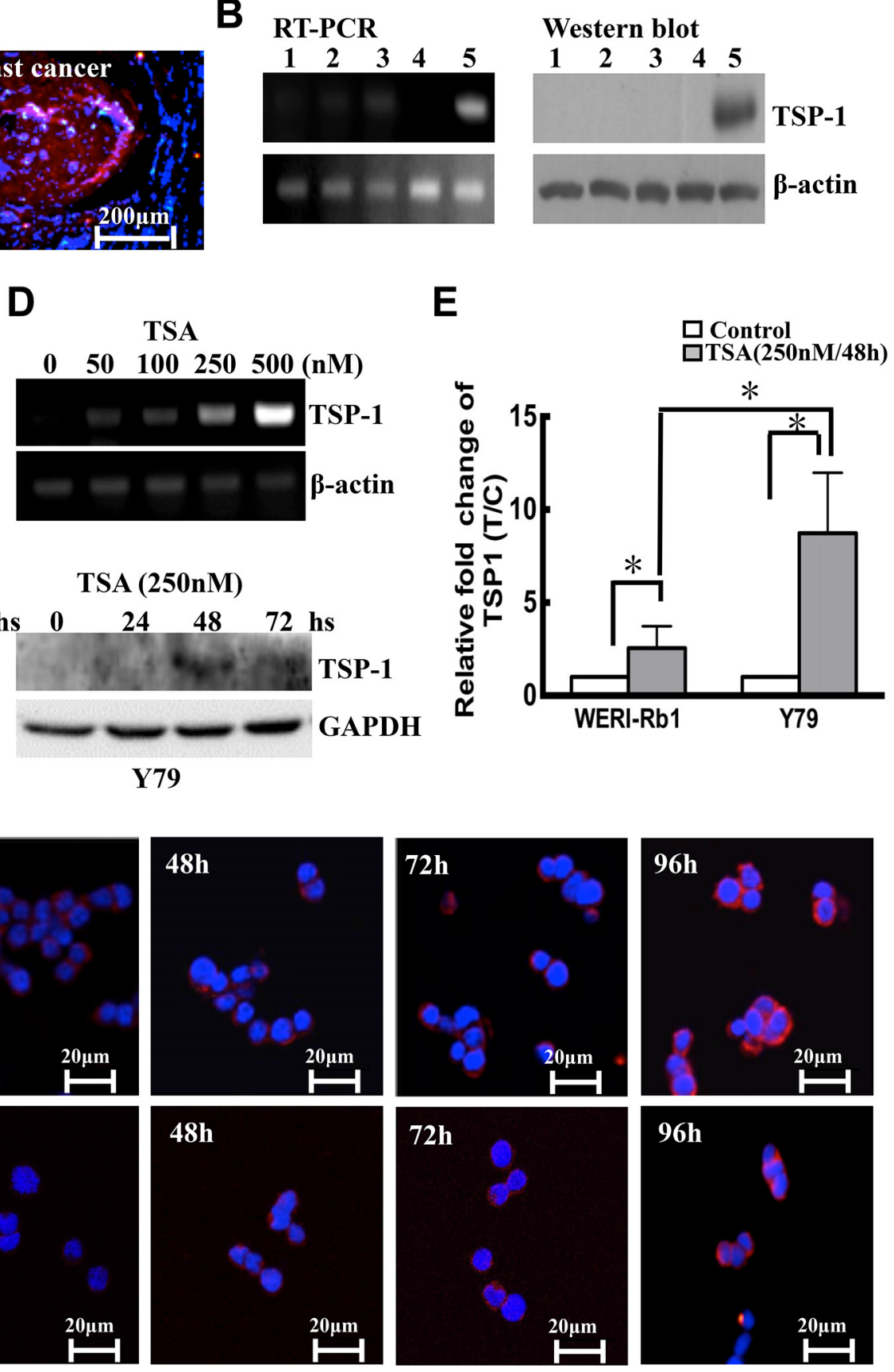

Figure 1: TSP-1 is silenced by histone deacetylation. A. Immunocytofluorescence showed that compared to the positive control, a lobular type of human breast cancer tissue sample, TSP-1 (red) was lacking in the human retinoblastoma. Original magnification, X 200. B. TSP-1 was not detectable in the 3 clinical human RB tumors (lane 1, 2,3) and WERI-Rb1 cells (lane 4) compared to Hela cells (lane 5) by RT-PCR and Western blot assay. C. Only TSA induced expression of TSP-1 in WERI-Rb1 cells. D. TSP-1 was induced by TSA in a dosedependent manner in WERI-Rb1 cells. E. TSP-1 levels in WERI-Rb1 and Y79 cells treated with TSA were analysed by real-time PCR. F. Western blot analysis of TSP-1 after TSA treatment. GAPDH was shown as an internal control. G. WERI-Rb1 and Y79 cells were stained by TSP-1 (red) at different time after treated with TSA $(250 \mathrm{nM})$. 
treated with 250 or $500 \mathrm{nM}$ TSA and were processed for CAT assay. As shown in Figure 2D, TSA significantly increased CAT activity in WERI-Rb1 cells in a dosedependent manner, compared to the controls (Control, 0; $250 \mathrm{nM}, 6.711 \pm 1.757 ; 500 \mathrm{nM}, 11.987 \pm 4.49$; respectively. $\left.{ }^{*} \mathrm{p}<0.05\right)$. Thus, these findings strongly supported that histone deacetylation was responsible for the silencing of TSP-1 in retinoblastoma.

\section{hTSP-1 inhibits cell viability and induces cell cycle arrest in WERI-Rb1 cells in vitro}

TSA could induce the re-expression of TSP-1 in both WERI-Rb1 cells and Y79 cells. However, TSA induced global acetylation in cells, which affected a massive number of genes. Thus, to evaluate the exact effects of TSP-1 on retinoblastoma cells, in parallel, hTSP-1 was added to the medium of the WERI-Rb1 cells and Y79

A

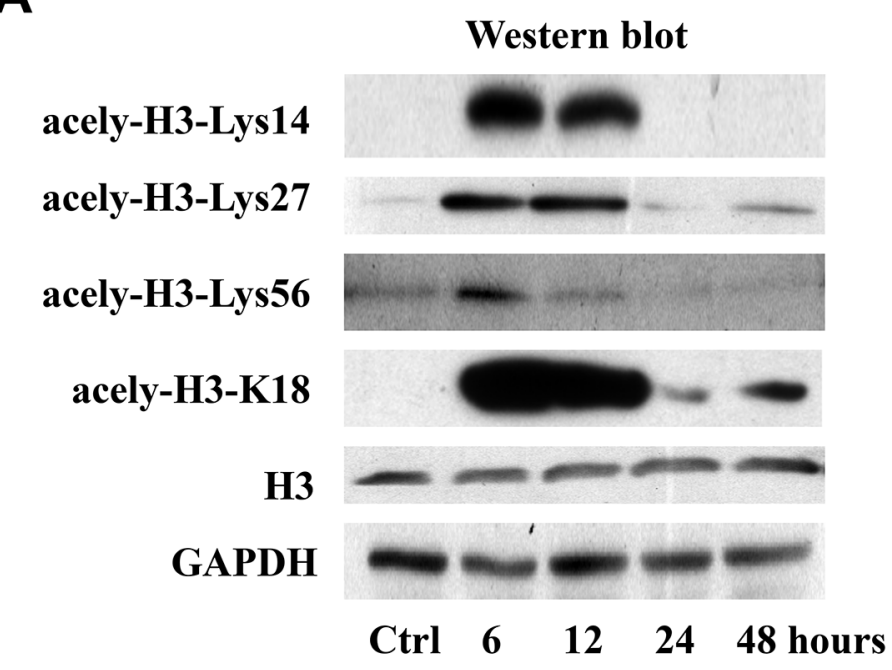

cells. Figure 3A shows the microscopic photographs of WERI-Rb1 cells and Y79 cells treated with 25 nM hTSP1 for $120 \mathrm{~h}$. Both the WERI-Rb1 and Y79 cells treated with hTSP-1 were much more scattered than the controls, which characteristically grew in loose, grape-like clusters. Furthermore, many cells presented massive membrane blebs among the cells treated with hTSP-1, while such blebs were completely absent in the untreated control cells, which might be a characteristic feature of apoptosis as part of a necrotic process. The growth-inhibitory effects of hTSP-1 on the human retinoblastoma cell lines WERI$\mathrm{Rb} 1$ and $\mathrm{Y} 79$ was evaluated in vitro at different time points using a CCK8 assay. Cell viability was represented by quantile normalization in $\log 2$ scale. As shown in Figure $3 \mathrm{~B}$, the viability of WERI-Rb1 cells treated with hTSP1 was significantly reduced continuously (hTSP-1, $24 \mathrm{~h}$, $-0.232 \pm 0.109 ; 48 \mathrm{~h},-0.313 \pm 0.050 ; 72 \mathrm{~h},-0.292 \pm 0.049$; $96,-0.432 \pm 0.089 ; 120 \mathrm{~h},-0.425 \pm 0.041$, respectively),

\section{B}
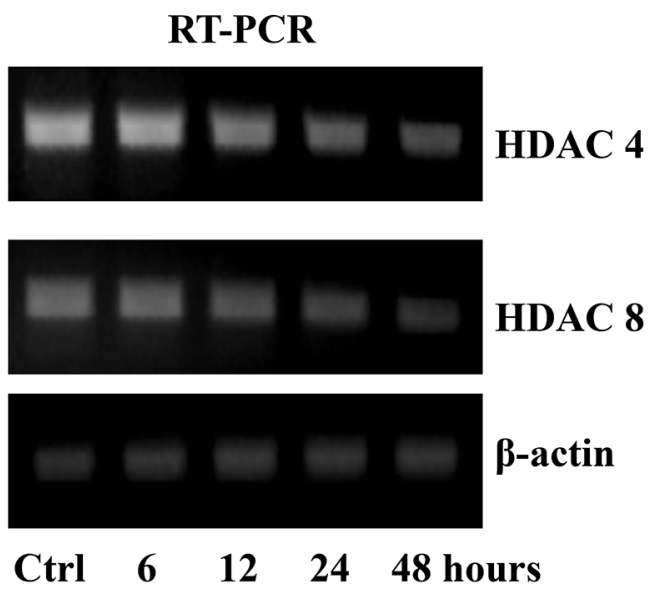

\section{$\begin{array}{lllll}\text { Ctrl } & 6 & 12 & 24 & 48 \text { hours }\end{array}$}

C
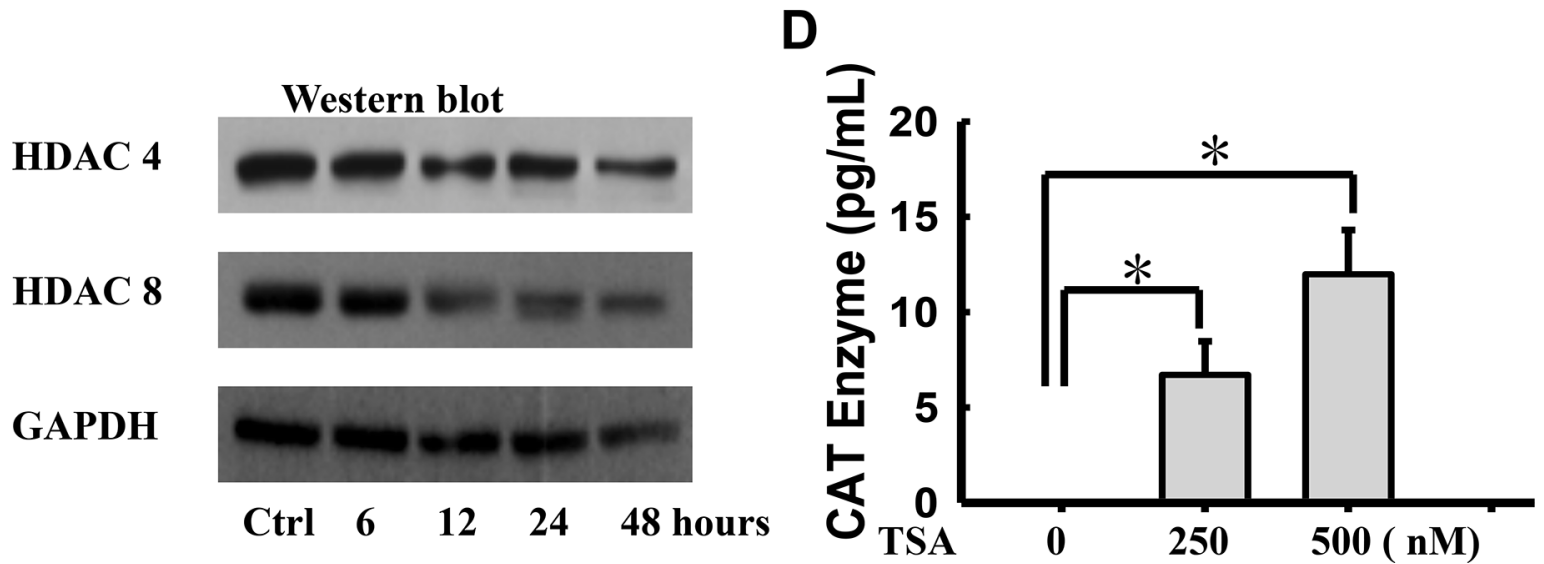

Figure 2: Histone deacetylase inhibitor transcriptionally induces expression of TSP-1 in WERI-Rb1 cells. A. Acetylated histone H3 (Lys14, 27, 56 and K18) protein levels were increased in TSA-treated (250 nM) WERI-Rb1 cells compare to the total histone H3. Analysis of RT-PCR B. and Western blot C. showed that TSA $(250 \mathrm{nM})$ notably induced the expression of HDAC4 and HDAC8 in WERI-Rb1 cells. D. CAT enzyme elisa of WERI-Rb1 cells treated with TSA for $24 \mathrm{~h}$ when transfected with the plasmid containing $-2033 /+750$ human TSP-1 promoter. $\beta$-actin or GAPDH was shown as an internal control. All results were confirmed in three independent experiments. *Statistically significant differences between the TSA and control $\left({ }^{*} \mathrm{p}<0.05\right)$. 
compared to the controls (Control, 0) $\left({ }^{*} \mathrm{p}<0.05,{ }^{*} \mathrm{p}<0.01\right)$, demonstrating that hTSP-1 could significantly inhibit the growth of WERI-Rb1 cells. Consistently, incubation with the exogenous hTSP-1 could also markedly inhibit the cell viability of Y79 cells (hTSP-1, $24 \mathrm{~h},-0.107 \pm 0.038 ; 48 \mathrm{~h}$, $-0.241 \pm 0.094 ; 72 \mathrm{~h},-0.408 \pm 0.102 ; 96,-0.381 \pm 0.114 ; 120$ h, $-0.489 \pm 0.083$, respectively) $\left({ }^{*} \mathrm{p}<0.05,{ }^{*} \mathrm{p}<0.01\right)$.

In addition, the incidence of early and late apoptosis induced by hTSP-1 in both WERI-Rb1 cells and Y79 cells was quantified by flow cytometry after Annexin V and PI staining. As shown in Figure 3C and 3E, TSP-1 could induce apoptosis in RB cells. Late but not early apoptosis was significantly induced in both WERI-Rb1 cells and Y79 cells followed 48 hours incubation with hTSP-1 (For WERI-Rb1, Early apoptosis: hTSP-1, 1.496 $\pm 0.69 \%$, Control, 0.72 $\pm 1.96 \%$, $\mathrm{p}>0.1$; Late apoptosis: hTSP-1, 10.366 $\pm 3.2 \%$, Control, $2.8 \pm 2.5 \%, * \mathrm{p}<0.05$ ) (For Y79, Early apoptosis: hTSP1, $1.547 \pm 0.43 \%$, Control, $2.166 \pm 1.36 \%, \mathrm{p}>0.1$; Late apoptosis: hTSP-1, 14.4 $\pm 1.14 \%$, Control, $1.176 \pm 1.15 \%$, $* * p<0.01)$. Moreover, as shown in Figure $3 \mathrm{~F}$, there was a decrease in the number of WERI-Rb1 cells in the G0/G1 phase (hTSP-1, 28.74 $\pm 7.30 \%$, Control, $42.74 \pm 5.70 \%, * p<0.05)$ and an increase in the number of cells in the S phase (hTSP-1, 47.00 $\pm 4.83 \%$, Control, $32.83 \pm 6.63 \% * \mathrm{p}<0.05$ ), whereas there was no significant difference in the number of cells in the G2 phase (hTSP1, 24.26 $\pm 2.48 \%$, Control, 24.43 $\pm 2.97 \%$, P $>0.1$ ). Similar result was obtained from Y79 cells treated with hTSP-1, demonstrating an S phase arrested (G0/G1 phase: hTSP-1, $68.56 \pm 2.42 \%$, Control, $82.81 \pm 6.11 \%,{ }^{*} \mathrm{p}<0.05$. S phase: hTSP-1, 22.19 $\pm 3.00 \%$, Control, $15.11 \pm 1.68 \%$, $* \mathrm{p}<0.05$. G2 phase: hTSP-1, $8.47 \pm 2.92 \%$, Control, $5.88 \pm 2.33 \%$, $\mathrm{p}>0.1$ ) (Figure 3G). These results showed that hTSP-1 could induce the impairment of cell cycle progression and induce S-phase arrest in WERI-Rb1 cells and Y79 cells. Taken together, these results indicated that TSP-1 could also significantly affect proliferation and viability and thus might be a potential therapeutic candidate for the treatment of resistant retinoblastoma.

\section{hTSP-1 might affect the repair of DNA DSBs by attenuating the NHEJ of WERI-Rb1 cells}

Previous studies have reported that failure of DNA double-strand breaks (DSBs) repair could induce S-phase arrest in the cell cycle [32]. To elucidate the mechanism of TSP-1-mediated S-phase arrest in RB cells, we analyzed the state of DNA DSBs in cells following exposure to hTSP-1. As shown in Figure 4A and 4B, hTSP-1 could significantly increase the expression of $\gamma$-H2AX in both WERI-Rb1 cells and Y79 cell by $7.53-$ fold and 10.1-fold, respectively, compared to the controls at $48 \mathrm{~h}$ after treatment $\left({ }^{*} \mathrm{p}<0.05\right)$. In addition, $\mathrm{P} 21$, which accumulated at DNA damage sites and was colocalized with $\gamma$-H2AX [33], was also up-regulated in WERI-Rb1 cells and Y79 cells treated with hTSP-1 by 2.86 -fold and 2.49-fold, respectively, compared to the controls $(* * \mathrm{p}<0.01)$, consistent with previous report that intact TSP-1 significantly induced increasing of P21 and DNA fragmentation in endothelial cells [20,34]. Therefore, these results indicated that TSP-1 might be involved in DNA DSBs repair in both WERI-Rb1 cells and Y79 cells. Dual immunofluorescence of $\gamma-\mathrm{H} 2 \mathrm{AX}$ and DAPI confirmed that $\gamma$-H2AX was present in most WERI-Rb1 cells as well as Y79 cells treated with hTSP-1 (Figure 4C). The ratio of $\gamma-\mathrm{H} 2 \mathrm{AX}$ foci-positive cells is represented as a histogram. As shown in Figure 4D, hTSP-1 significantly resulted in a marked increase in $\gamma$-H2AX staining (WERIRb1: $16.53 \pm 5.41 \%, Y 79: 22.79 \pm 4.62 \%$ ), compared to the controls (WERI-Rb1: $2.90 \pm 1.20 \%$, Y79: $14.98 \pm 2.93 \%$, $* * \mathrm{p}<0.01)$.

DNA DSBs repair includes homologous recombination (HR) and DNA non-homologous end joining (NHEJ) [35]. To reveal whether TSP-1 was involved in both pathways, we further assessed NHEJ and HR activities of WERI-Rb1 cells. The structure of the NHEJ and HR substrate and the strategy to measure NHEJ and HR have been described previously [36, 37] and are depicted in Figure 4E; this strategy was previously developed and has been successfully used to define the roles of BRCA1, Rb1, Mre11, XRCC4 and Ku80 in the control of DNA DSBs repair in human cells $[32,35,38-40]$. For NHEJ, the plasmid pEPINHEJ contains a human S/MAR [41], which stably and independently replicates in WERI-Rb1 cells. Moreover, there are two I-SceI recognition sites before the reporter gene GFP. An artificial ATG (ATGART) between the two sites induces a translational shift, hence preventing GFP luciferase reporter gene expression. After digestion with I-SceI, fully complementary cohesive 3-OH singlestranded ends of four bases are produced upon double cleavage. If rejoining of the double-stranded ends by NHEJ occurs, then the intact GFP can be translated and expressed in cells. Alternatively, error-prone NHEJ at either of the single I-SceI sites can disrupt ATGART, which also allows for the expression of GFP. In contrast, precise re-ligation at a single I-SceI site cannot be detected directly by flow cytometry analysis using this system. The prevalence of GFP-positive cells represents the overall proficiency of NHEJ. For HR, the plasmid pEPI-HR is similar to the NHEJ substrate, which contains two GFP cDNA fragments after the promoter: GFP1 occurs at +1 to $+400 \mathrm{bp}$, and GFP2 covers the whole cDNA. There is an inserter between GFP1 and GFP2, which results in the abnormal expression of GFP. After digestion with I-SceI, HR ends are produced. If HR occurs, GFP is expressed by sharing an extensive sequence homology. The prevalence of GFP-positive cells represents the overall proficiency of HR.

To define the role of TSP-1 in the DSB repair pathway, WERI-Rb1 cells carrying the episomally 

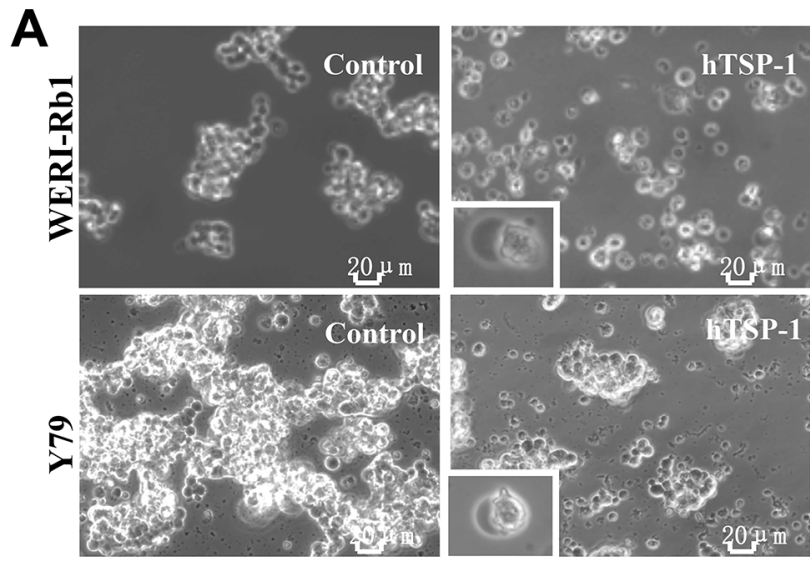

B
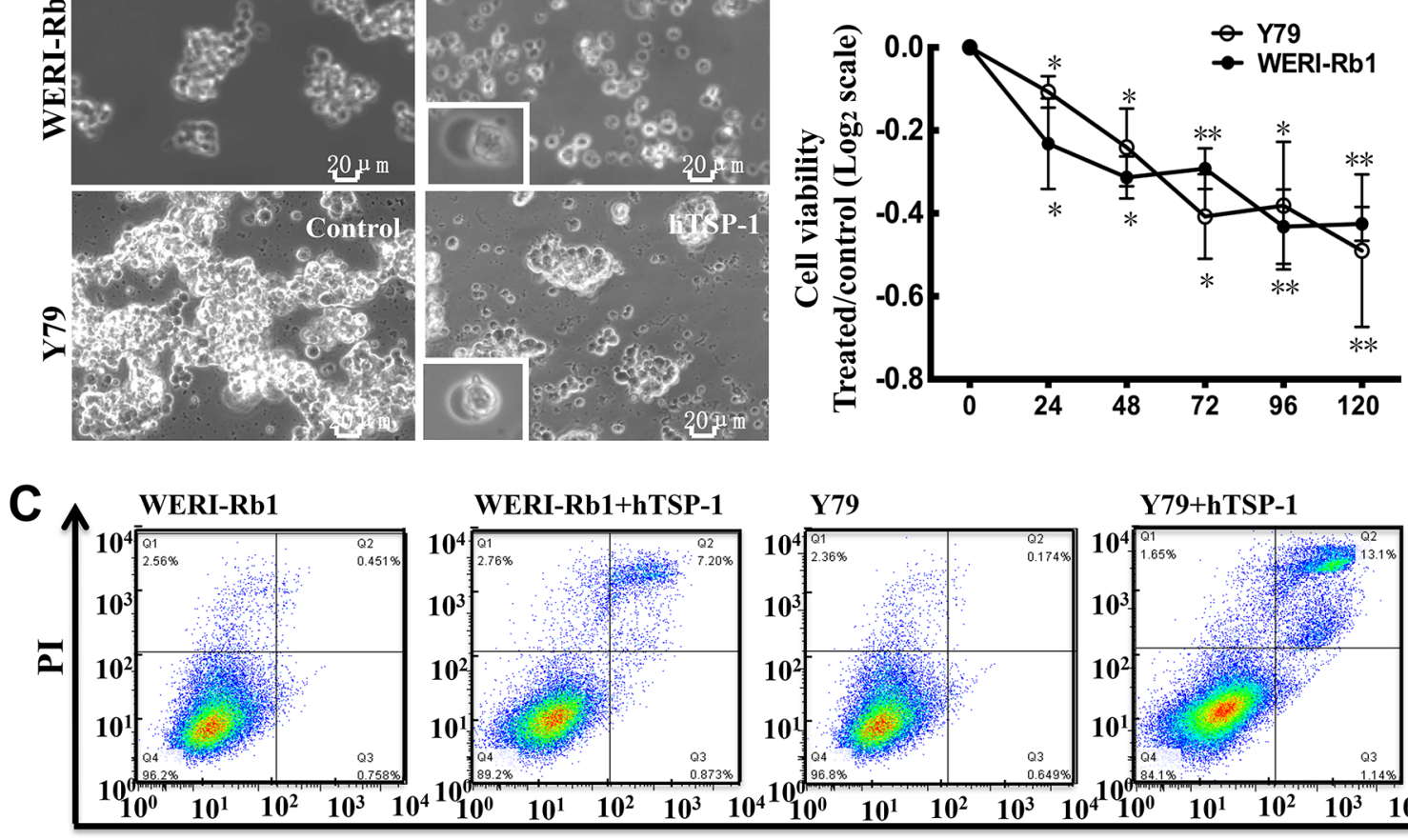

D

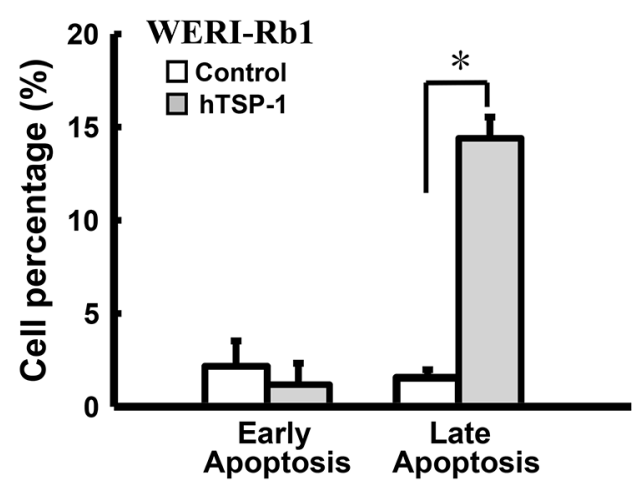

$\mathbf{F}$

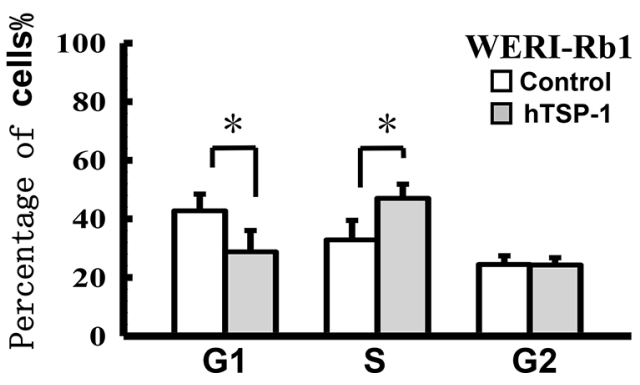

$\mathbf{E}$
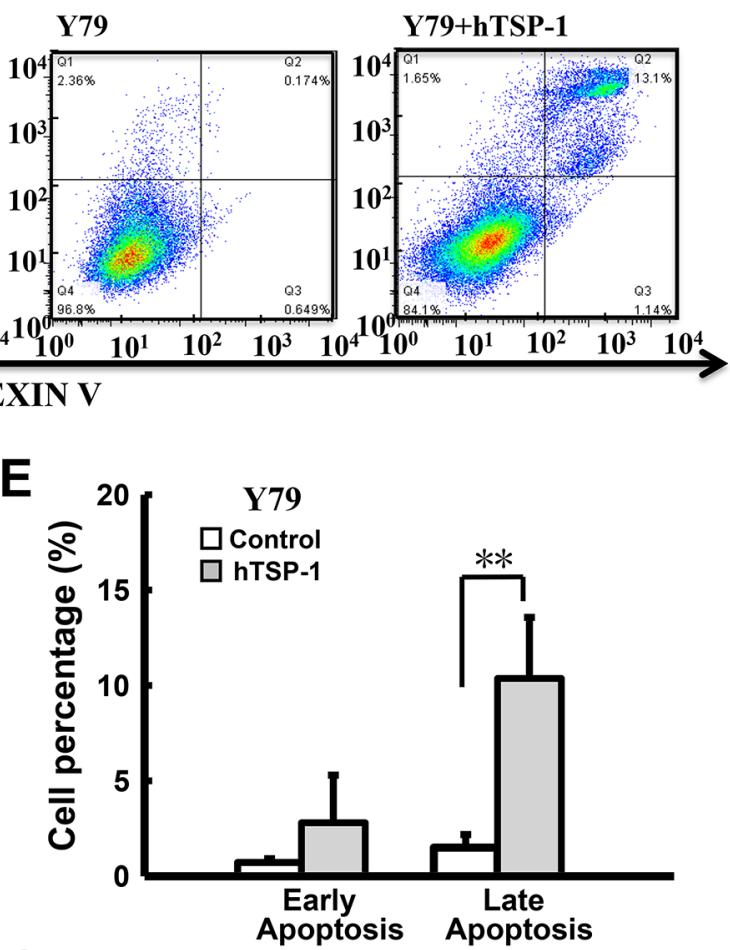

G

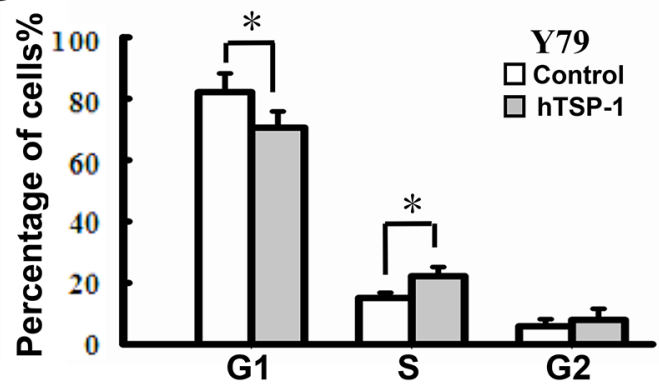

Figure 3: hTSP-1 affects cell viability and the cell cycle of WERI-Rb1 and Y79 cells. A. The morphology changes of WERIRb1 and Y79 cells treated with hTSP-1 (25 nM) for 120h. The cells showed membrane blebs (bottom left pictures) after hTSP-1 treatment. B. hTSP-1 inhibited the viability of WERI-Rb1 and Y79 cells compared to negative controls. The results of the CCK8 assays were plotted on a $\log 2$ scale. C. The early apoptosis and cell death of WERI-Rb1 and Y79 cells was quantified by flow cytometry after Annexin V and propidium iodide staining. D, E. The percentages of early and late apoptotic WERI-Rb1 and Y79 cells are presented in histograms. The data showed that hTSP-1 had no effect on the incidence of early apoptosis, however, could markedly increase the incidence of late apoptosis in both of the cells. F, G. hTSP-1 impaired S-phase progression in both WERI-Rb1 cells and Y79 cells after hTSP-1 treatment for $24 \mathrm{~h}$ compared to the control. In addition, there was no significant difference in the G2 phase G2/M in WERI-Rb1 cells and Y79 cells. *Statistically significant differences between the TSA and control $(* \mathrm{p}<0.05, * * \mathrm{p}<0.01)$. 

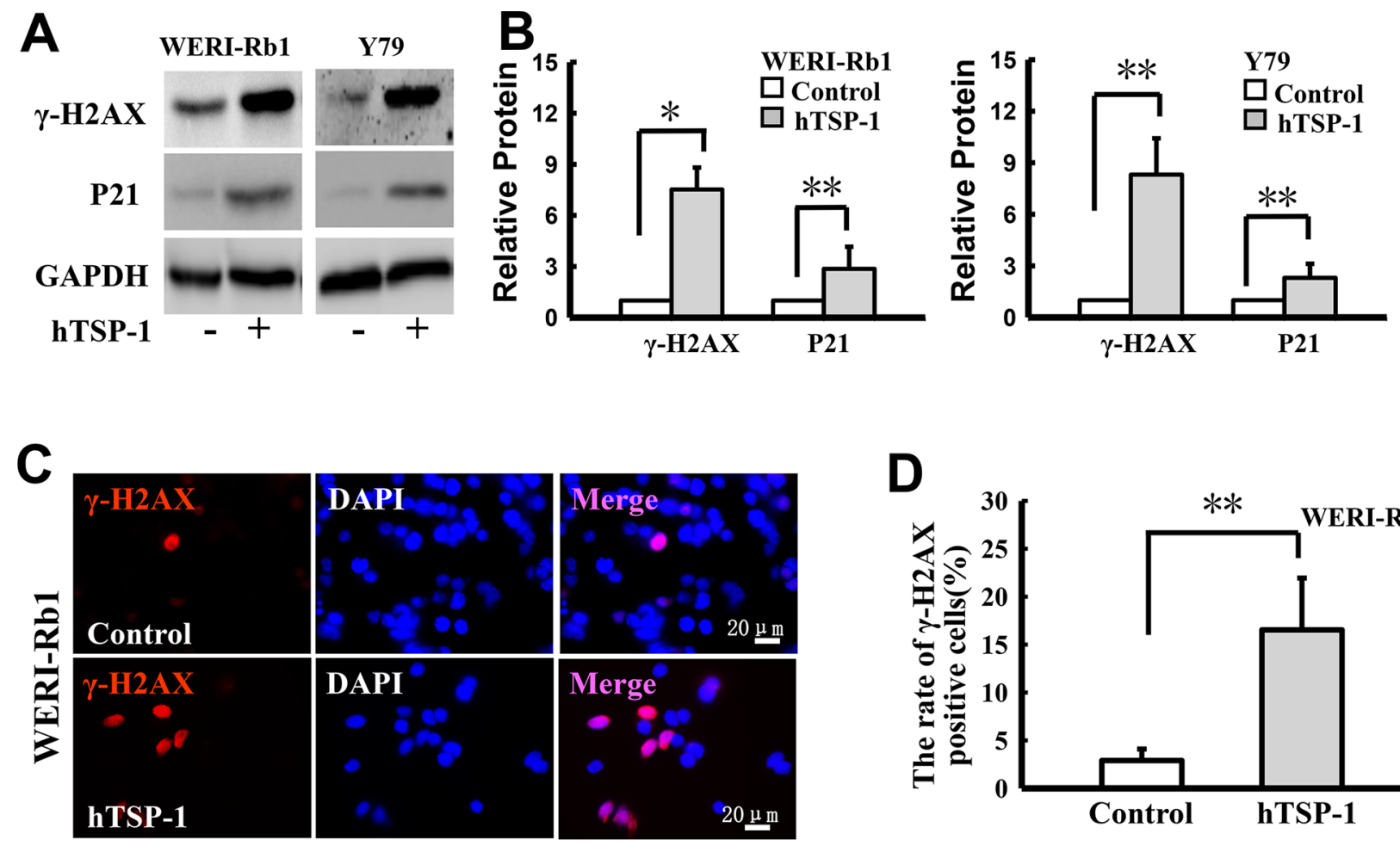

D
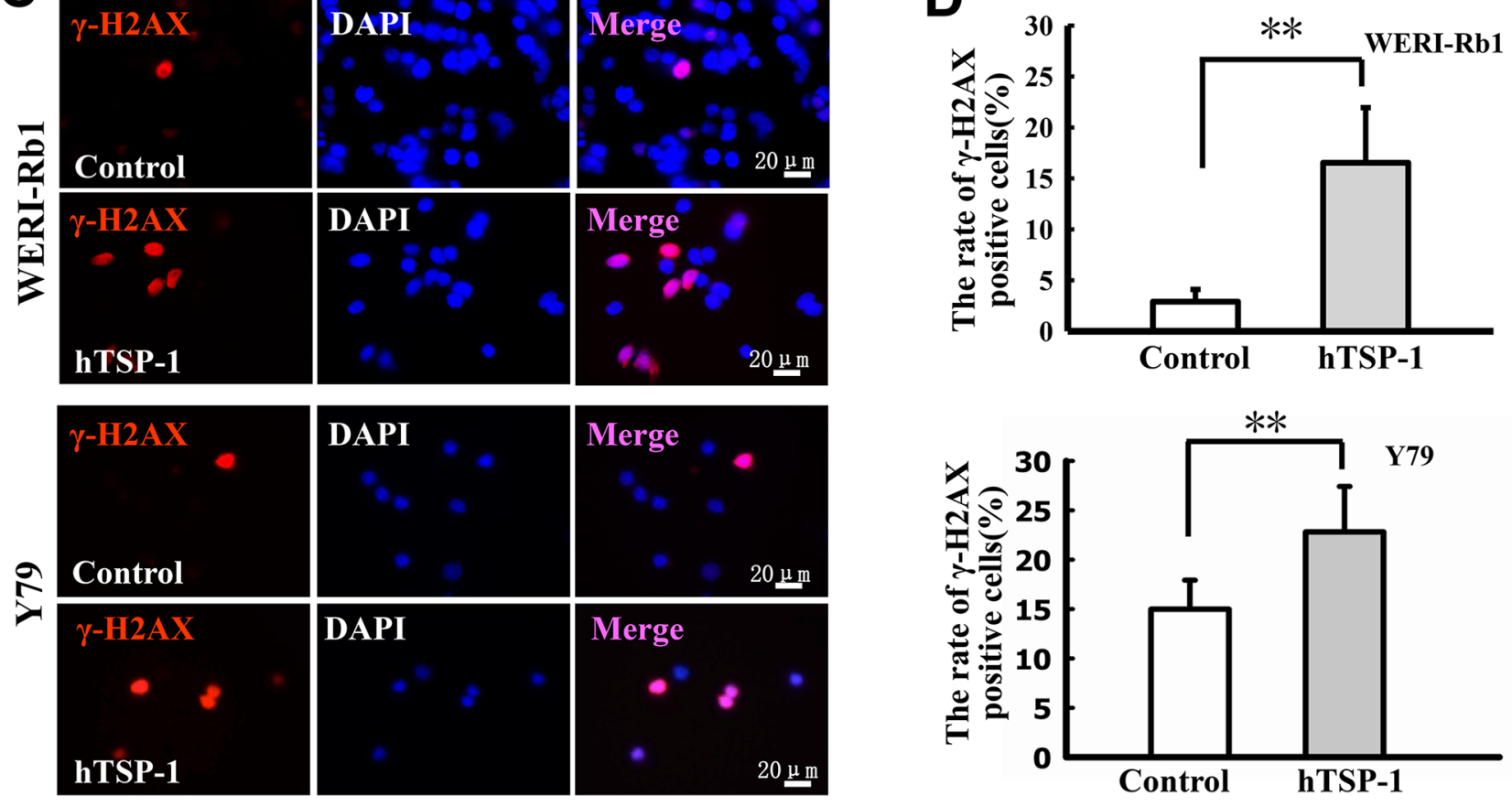

$\mathbf{E}$
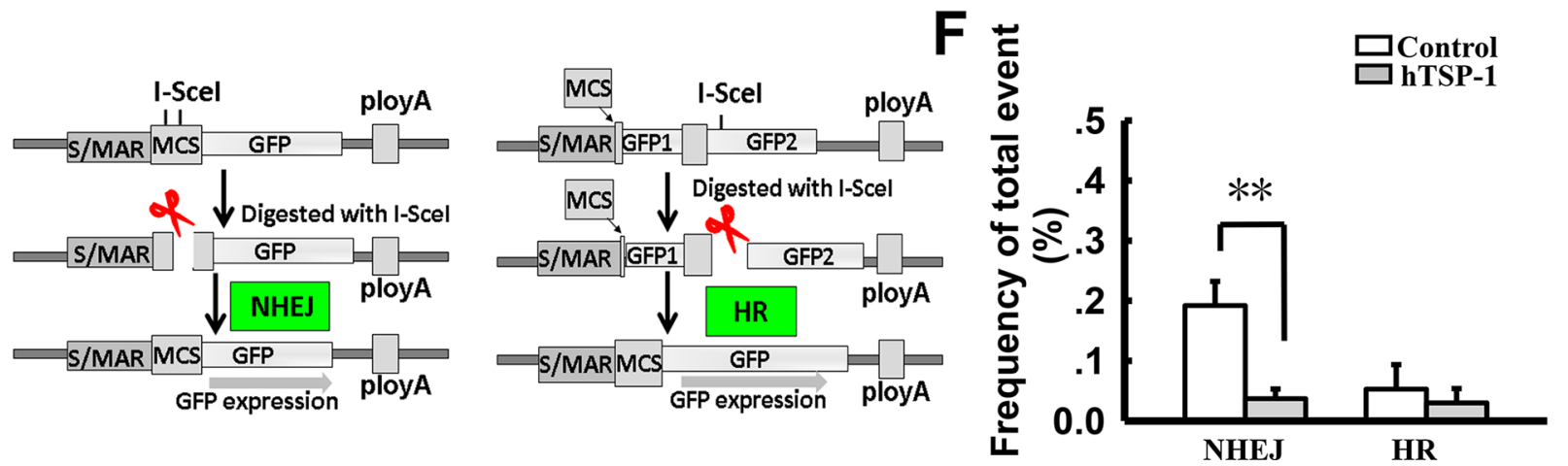

Figure 4: hTSP-1 induces DNA double-strand breaks and affects the NHEJ in WERI-Rb1 and Y79 cells. A. Western blot analysis of $\gamma$-H2AX and P21 in WERI-Rb1 and Y79 cells with or without hTSP-1 treatment for $48 \mathrm{~h}$. GAPDH was shown as an internal control. B. Relative quantification of expression of $\gamma$-H2AX in WERI-Rb1 and Y79 cells was quantified by densitometry. C. $\gamma$-H2AX (red) was present on WERI-Rb1 and Y79 cells treated with hTSP-1. D. The relative quantification of $\gamma$-H2AX expression following hTSP-1 was determined by counting foci in 50 randomly positive cells, and these data were graphically represented, and indicated that hTSP-1 significantly increases DNA DSBs in WERI-Rb1 and Y79 cells. E. The structure of the NHEJ and HR substrate and the strategy to measure NHEJ and HR. F. Overall I-SceI-induced DSB end-rejoining efficiency in WERI-Rb1/pEPI-NHEJ and WERI-Rb1/pEPI-HR with or without hTSP-1 in WERI-Rb1, as measured by flow cytometry. Significant difference in the repair efficiency of NHEJ with hTSP-1 versus the control treatment was represented as a histogram. Asterisks indicate statistically significant differences between the control and test cells $(* \mathrm{p}<0.05, * * \mathrm{p}<0.01)$. 
replicating $\mathrm{pEPI-NHEJ}$ or pEPI-HR substrate were treated with $25 \mathrm{nM}$ hTSP-1. At twenty-four hours after treatment, the cells were transfected with the I-SceI endonuclease-expressing plasmid. At $48 \mathrm{~h}$ after transfection, the cells were harvested and analyzed by flow cytometry. Comparison with the data in Figure $4 \mathrm{~F}$ demonstrated that the relative efficiency of NHEJ in the WERI-Rb1 cells treated with hTSP$1(0.192 \pm 0.040 \%)$ was significantly lower than in the controls $(0.037 \pm 0.016 \%)(* p<0.05)$. In contrast, the rejoining levels in the cells revealed that hTSP-1 had no differential effects on HR in WERI-Rb1 cells (hTSP-1, $0.053 \pm 0.040 \%$; control, $0.030 \pm 0.024 \%, \mathrm{p}>0.05)$. Thus, these findings provided direct evidence that TSP-1 might inhibit DNA NHEJ pathway in WERI-Rb1 cells. In addition, we performed NHEJ and HR assay in Y79. However, transfection efficiency in Y97 cells (1\%) is notably low than that of WERI-Rb1 cells (12\%). The efficiency of DNA DSBs repair in the assay is very low too. Thus, the results from Y79 cells are not significant in NHEJ and HR assay.

A

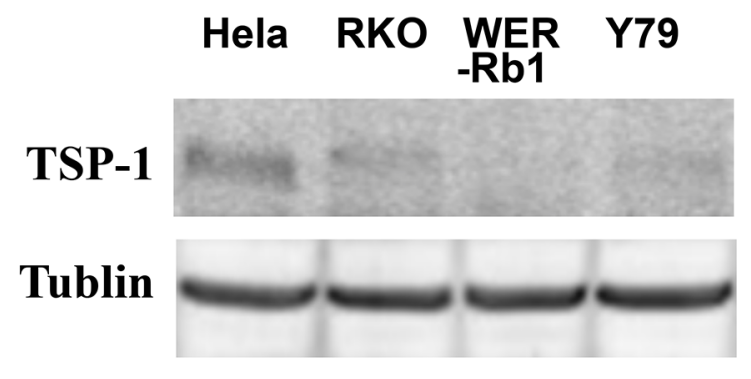

C

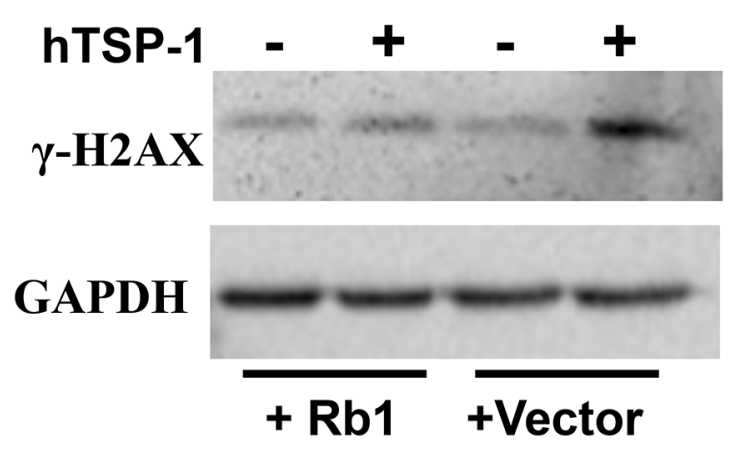

The mutation of Rb1 might be involved in TSP1-mediated DNA DSBs repair in WERI-Rb1 cells

As previous study, the bioactivity of TSP-1mediated DNA repair is associated with cell type [22]. Therefore, we further investigated whether the mutation of $\mathrm{Rb} 1$ is involved in TSP-1-mediated DNA repair in RB cells. We measured $\gamma-\mathrm{H} 2 \mathrm{AX}$ in RKO cells, a line of poorly differentiated colon carcinoma cells. Our data is consistent with the previous report that TSP-1 is silenced in RKO cells by high DNA methylation [42] (Figure 5A). Interestingly, as shown in Figure 5B, hTSP-1 could not alter the expression level of $\gamma-\mathrm{H} 2 \mathrm{AX}$ in RKO cells, compared to that of the controls. Thus, attenuating DNA DSBs repair by TSP-1 might be specific to RB cells.

Because the up-regulation of $\gamma$-H2AX TSP-1mediated occurs in $\mathrm{RB}$ cells instead of RKO cells, we speculated that $\mathrm{Rb} 1$, a transcription co-regulator, might be involved in this process. To elucidate this hypothesis, WERI-Rb1 cells were transfected with the pEPI-GFP-Rb1 plasmid, expressing wide-type Rb1 and GFP, or the pEPI-

B

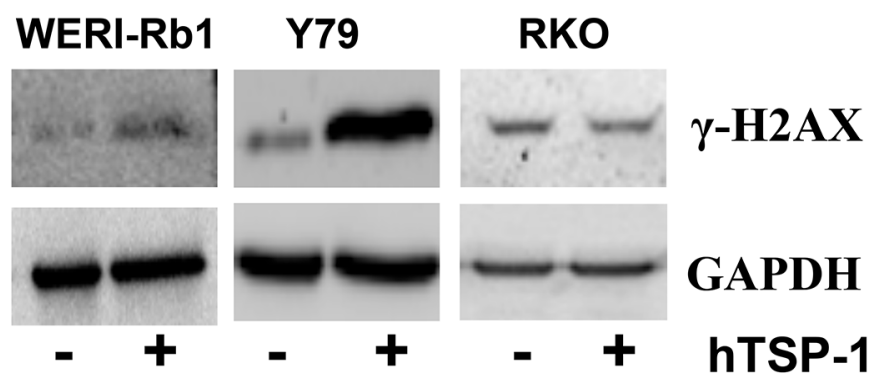

D

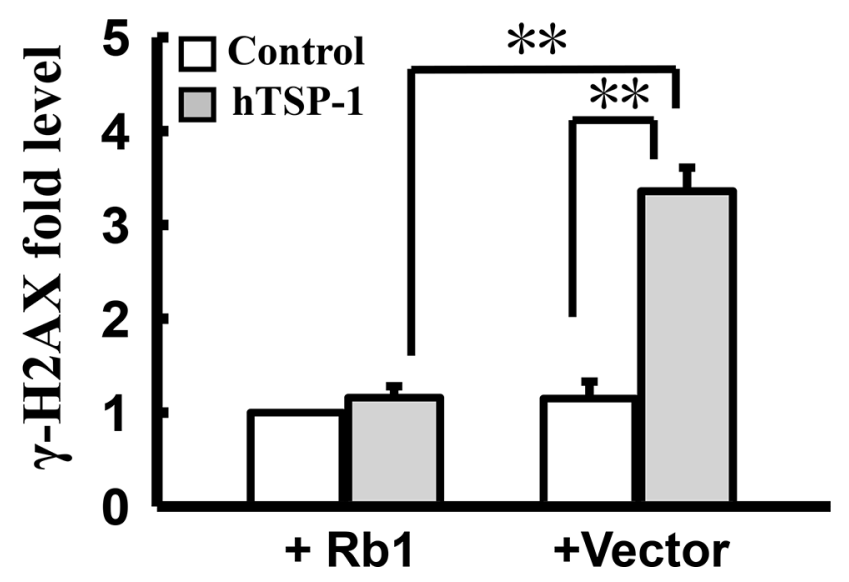

Figure 5: Attenuating DNA NHEJ repair by TSP-1 is specific to WERI-Rb1 cells. A. Western blot assay showed that TSP1 was silenced in RKO cells, WERI-Rb1cells and Y79 cells, compared to the positive cells Hela cells. B. Western blot assay showed that hTSP-1 did not affect the expression level of $\gamma$-H2AX in RKO cells compared with WERI-Rb1 cells and Y79 cells. C. Exogenous $\mathrm{Rb} 1$ remarkably attenuated hTSP-1-induced increase of $\gamma$-H2AX in WERI-Rb1 cells after transfected with pEPI-GFP-Rb1. D. Relative quantification of expression of $\gamma$-H2AX in WERI-Rb1 cells was quantified by densitometry. The expression of $\gamma$-H2AX in WERI-Rb1 cells expressing exogenous Rb1 was not affected compared to the control cells transfected with vector. Exogenous Rb1 significantly attenuated the hTSP-1-induced up-regulation of $\gamma$-H2AX in WERI-Rb1 cells. GAPDH was shown as an internal control. Asterisks indicate statistically significant differences between the control and test cells $(* * \mathrm{p}<0.01)$. 
vector. GFP-positive cells represented cells expressing exogenous Rb1. Following treatment with hTSP-1, whole lysates of WERI-Rb1 cells with and without exogenous $\mathrm{Rb} 1$ were extracted at $48 \mathrm{~h}$ post-treatment. Western blot analysis indicated that exogenous $\mathrm{Rb} 1$ could significantly attenuate the hTSP-1-induced up-regulation of $\gamma-\mathrm{H} 2 \mathrm{AX}$ in WERI-Rb1 cells (wild-type Rb1, 1.15 \pm 0.18 ), compared to the control cells (vector, 3.36 \pm 0.25 ) (Figure 5C, 5D) $(* * p<0.01)$. The expression of $\gamma-\mathrm{H} 2 \mathrm{AX}$ in Y79 was not changed, which might be caused by low transfect efficiency (data not shown). Therefore, these results suggested that a mutation of Rb1 might be involved in the TSP-1-mediated DNA DSBs repair in WERI-Rb1 cells.

\section{hTSP-1 could inhibit WERI-Rb1 cells and promote retina neurocyte survival in the neuronal and retinoblastoma cell co-culture system}

Based on previous studies, in which TSP-1 could promote retinal neural survival [28-30], we further defined whether TSP-1 could play the role of a doubleedged sword in the inhibition of retinoblastoma growth and the protection of neurocytes. Therefore, a coculture system was established to mimic physiological conditions, in which WERI-Rb1 cells were cultured in the top chamber and retinal neurons in the bottom chamber. The cells were treated with 25 nM hTSP-1 for 4 days. As shown in Figure 6A and 6B, the expression of synaptophysin, a downstream protein of TSP-1 involved in synaptogenesis [26], in retinal neurocytes was notably up-regulated by TSP-1 according to immunohistochemical analysis and western blot assay (Figure 6A, 6B). Moreover, the results of the CCK8 assay revealed that the cell viability of neurocytes treated with hTSP-1 was not affected on the first day, compared to the controls. However, at days 2, 3 and 4 after treatment, hTSP-1 could significantly increase the viability of neurocytes, compared to the controls by quantile normalization in $\log 2$ scale (hTSP-1, D2, $0.188 \pm 0.104, \quad$ D3 $, \quad 0.212 \pm 0.099, \quad$ D4, $0.183 \pm 0.049$, respectively; Control, $0 ; * \mathrm{p}<0.05, * * \mathrm{p}<0.01$ )(Figure $6 \mathrm{C})$. In contrast, the growth of WERI-Rb1 cells in the top chamber was significantly inhibited by hTSP-1 beginning on the second day after treatment, compared with the controls (hTSP-1, D1, $-0.0178 \pm 0.03$, D2, $-0.182 \pm 0.103$, D3, $-0.312 \pm 0.023$ and $\mathrm{D} 4,-0.364 \pm 0.044,{ }^{*} \mathrm{p}<0.05$, $*^{* *} \mathrm{p}<0.01$ )(Figure 6C). Moreover, hTSP-1 exerted significantly neuroprotective activity and inhibition effect on Y79 cells too (For retinal neurons: hTSP-1, D1, 0.034 \pm 0.093 D2, 0.042 \pm 0.033 ; D3, 0.064 \pm 0.034 ; D4, 0.190 \pm 0.098 , respectively; Control, 0 ; ${ }^{*} \mathrm{p}<0.05$; For Y79: D1, $-0.083 \pm 0.059$, D2, $-0.473 \pm 0.079$; D3, $-0.352 \pm 0.072$; D4, $-0.415 \pm 0.195$, respectively; Control, $0 ; * p<0.05, * * p<0.01$ ) (Figure 6D). Therefore, our data indicated that TSP-1 suppressed RB cells growth and had neuroprotective ability in this co-culture system.

\section{hTSP-1 could inhibit retinoblastoma formation} in vivo

To validate our findings of TSP-1-mediated inhibition of retinoblastoma cells, we performed a tumor-response experiment using our mice xenograft model. A total of $2 \times 10^{5}$ WERI-Rb1 cells were injected into the vitreous of right eyes. Two weeks after tumor implantation, the nude mice were randomized to different groups receiving injections of hTSP-1 or balanced salt solution for two weeks. Figure 7A showed that the degree of exophthalmos in the WERI-Rb1 implantation mice treated with hTSP-1 was clearly smaller than that of the controls. In addition, hematoxylin and eosin staining of representative retinoblastoma tumor showed the structure of right eye was destroyed. Briefly, fundus photography showed that tumor growth was significantly inhibited in mice treated with hTSP-1, compared with that in the control mice (Figure 7B) (black arrowhead). Because the degree of exophthalmos was positively related to the growth of tumors, we used axial length and volume of the eyeball, which were previously used in clinical and experimental assays [43, 44], to represent tumor growth. In hTSP-1 group, the axial length ratio of eyeballs $\left(\mathrm{L}_{\text {TSP. }}\right.$. 1-right $\left./ \mathrm{L}_{\text {TSP-1-left }}\right)$ was $1.33 \pm 0.132$, compared to the controls $\left(\mathrm{L}_{\text {CON-right }} / \mathrm{L}_{\text {CON-leff }}\right)$, in which it was $1.51 \pm 0.301(* * \mathrm{p}<0.01)$ (Figure 7C). Furthermore, the volume ratio of eyeballs $\left(\mathrm{V}_{\text {TSP-1-right }} / \mathrm{V}_{\text {TSP-1-left }}\right)$ was $2.37 \pm 0.645$, and for the control groups, the volume ratio of eyeballs $\left(\mathrm{V}_{\text {CON-right }} / \mathrm{V}_{\text {CON-left }}\right)$ was $3.58 \pm 1.903(* * p<0.01)$ (Figure 7D). These data were consistent with our results from WERI-Rb1 cells in vitro, suggesting that TSP-1 suppressed tumor growth, compared to the controls.

\section{DISCUSSION}

In the present study, our results showed that TSP-1 might be a therapeutic target to suppress retinoblastoma growth. First, we found that TSP-1 was silenced in RB tumors cells by histone deacetylation. HDAC inhibitor TSA could significantly induce the re-expression of TSP-1 in WERI-Rb1 cells and Y79 cells. hTSP-1 could significantly suppress the growth of RB cells both in vitro and in vivo. In addition, using a retinoblastoma-neuronal co-culturing system, we also demonstrated that TSP-1 could significantly inhibit RB cells while promoting retinal neurocyte survival. These results indicated therapeutic potential of TSP-1 in the treatment of retinoblastoma. Moreover, we revealed a mechanism, which we believe to be novel, by which TSP-1 could significantly induce $\gamma$-H2AX foci, which is a well-characterized in situ marker of DNA DSBs in both WERI-Rb1 cells and Y79 cells. Consistent with role of $\gamma$-H2AX, TSP-1 inhibited the DNA NHEJ pathway in WERI-Rb1 cells. Apoptosis assay also demonstrated that TSP-1 could induce apoptosis in RB cells. Furthermore, our study revealed that the mutation of Rb1 might be involved in the TSP-1-medicated DNA 
DSBs repair in WERI-Rb1 cells. Thus, our present findings provided direct biochemical and functional evidence supporting the notion that TSP-1 might be a therapeutic target to suppress retinoblastoma growth by regulation of DNA DSBs repair.

The first thrombospondin to be identified, TSP1 , is a potent inhibitor of angiogenesis and has complex effects on tumor development [3]. Our data showed that TSP-1 was silenced in both WERI-Rb1 cells and Y79 cells. Moreover, our results indicated that the mechanism of TSP-1 silencing of WERI-Rb1 cells was involved in histone deacetylation, different from that of other neuroblast tumors. Yang et al reported that DNA methylation played a dominant role in neuroblastoma cells [10].

TSP-1 appears to play numerous and complex roles in cancer growth and metastasis. The multimodular structure of TSP-1 confers to these molecules anti-tumoral as well as pro-tumoral properties [3, 45]. This apparent discrepancy depends on the cell type or tissue studied. At present, only several studies have demonstrated that TSP-1 is involved in DNA damage. Guo et al reported that TSP-1 analogues induced programmed cell death in endothelial cells, based on morphological changes, assessment of DNA fragmentation, and internucleosomal DNA cleavage. Intact TSP-1 also induced DNA fragmentation in endothelial cells [22]. However, the mechanism of DNA repair TSP-1-medicated remains obscure. There is a report indicating that TSP-1 might stimulate reactive oxygen species production by signal-regulatory protein- $\alpha$ in ischemia reperfusion injury. Our data demonstrated that TSP-1 could significantly increase the expression levels of $\gamma-\mathrm{H} 2 \mathrm{AX}$ and P21, which are markers of DNA DSBs in WERI-Rb1 cells and Y79 cells. Moreover, TSP-1 might significantly inhibit DNA NHEJ pathway, whereas it did not affect HR events in WERI-Rb1 cells. Therefore, TSP-1 may be involved in DNA DSBs repair in RB cells.

Interestingly, TSP-1 did not affect the expression of $\gamma-\mathrm{H} 2 \mathrm{AX}$ in RKO cells, indicating that the attenuation of the DNA DSBs repair pathway by TSP-1 was specific to $\mathrm{RB}$ cells. Consistent with our hypotheses, exogenous Rb1 could attenuate the increase of $\gamma-\mathrm{H} 2 \mathrm{AX}$ in WERI-Rb1 cells after TSP-1 treatment. Thus, these results indicated that a mutation of Rb1 might be involved in TSP-1-mediated suppression of DNA DSBs repair. Currently, it has been clear that the complex of the Rb1 binding transcript factor E2F plays a crucial role in regulating transcription. Much evidence has demonstrated that the complex of $\mathrm{Rb} 1$ and E2F regulates many downstream target genes that are involved in cell cycle progression and DNA replication
A
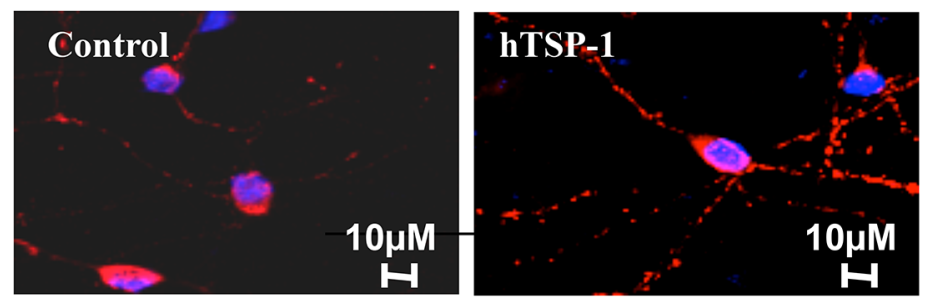

B

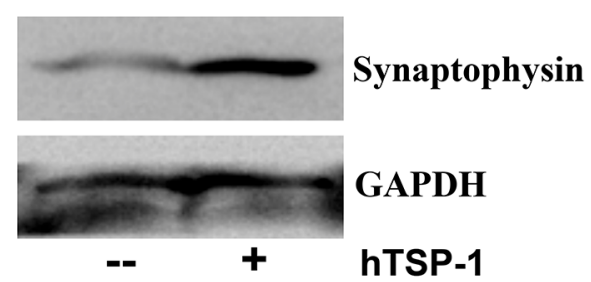

C

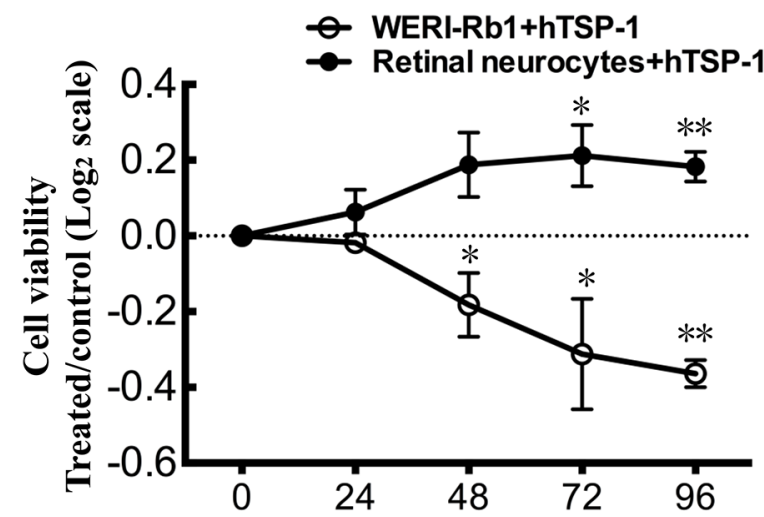

D

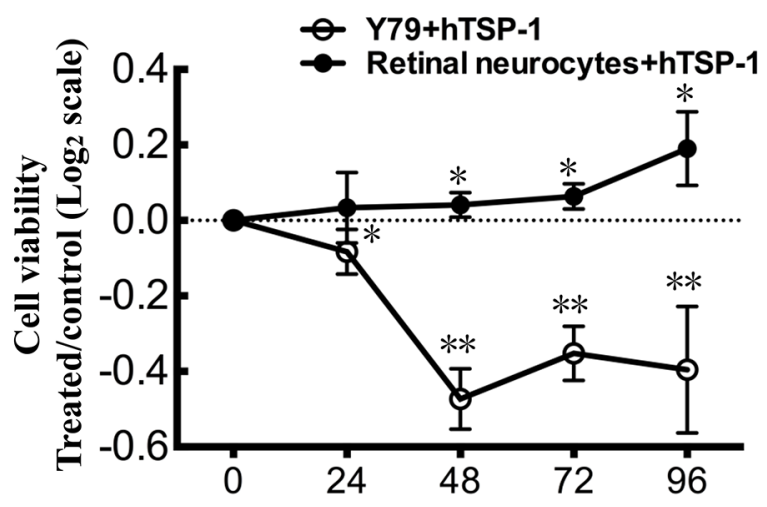

Figure 6: hTSP-1 inhibits WERI-Rb1 and Y79 cells, whereas, promote retina neurocytes survival in co-culture. A. Immunohistochemical analysis of retina neurons for synaptophysin (red) showed more synaptic puncta, compared to the control. B. hTSP1 increased the expressing level of synaptophysin in retinal neurocytes by western blot assay. C. CCK8 assay indicated that hTSP-1 significantly increased the cell viability of retina neurons days compared to the control. Growth of WERI-Rb1 cells was significantly inhibited by hTSP-1 compared to the control. The results of the CCK8 assays were plotted on a $\log 2$ scale. D. CCK8 assays of retina neurons and Y79 cells co-culture system treated with hTSP-1. The data was plotted on a log2 scale. 
[46]. However, the direct evidence of Rb1 and TSP-1 in DNA DSBs repair has been not reported yet. One study indicated that the suppression of TSP-1 could be achieved by an alternative mechanism involving the inactivation of both $\mathrm{p} 53$ and $\mathrm{pRb}$ [47]. In addition, Thrombospondin-1 signaling through CD47 inhibits self-renewal by negative regulating c-Myc and other stem cell transcription factors, such as, c-Myc, Klf4, Oct4, and Sox2 [48]. Therefore, we speculate that TSP-1 is not only a matricellular protein associated with cell migration and invasive, but also a possible transcription factor in regulation of other genes.
There might be a complicated mechanism of TSP-1mediated DNA DSBs repair in retinoblastoma cells, which is required to be investigated in the future.

Furthermore, it is well known that retinoblastoma develops in the retina, which develops rapidly in early life, and results in neural damage [42]. Some reports have indicated that TSP-1 plays a key role in neural development and promoting synaptic activity [24, 49-50]. Synaptic activity could suppress Puma-induced neuronal apoptosis [28]. An increase in synaptic activity could enhance neuronal survival $[28,29]$. Compared with WT
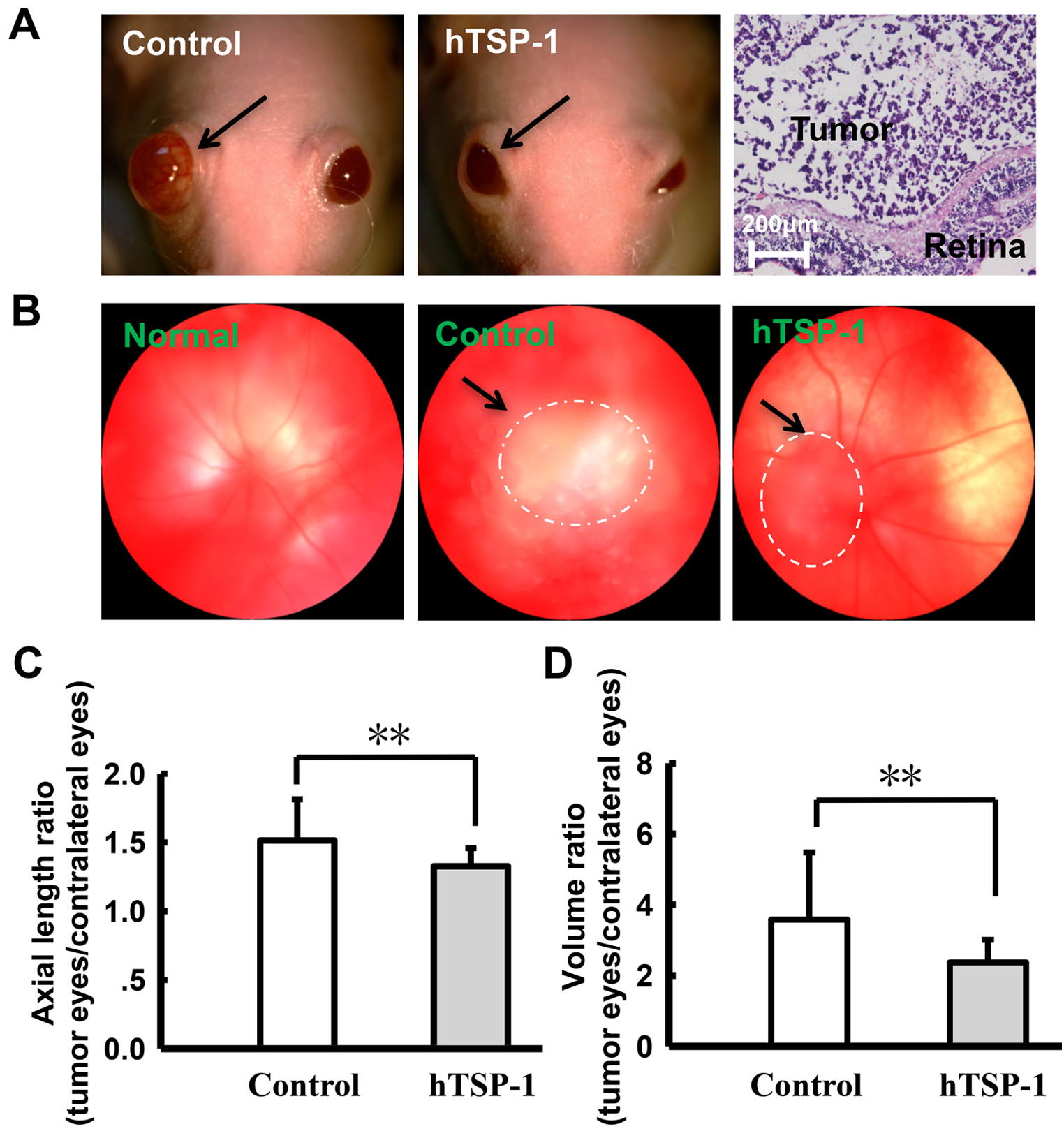

Figure 7: hTSP-1 suppresses the growth of retinoblastoma A. photographs of nu/nu nude mice retinoblastoma xenografts. The degree of exophthalmos was significantly decreased after treated with hTSP-1, compared to the control (arrow). B. Fundus photograph taken photos of normal, control and hTSP-1 treatment group in 30 days. The images showed that hTSP-1 inhibited tumor growth compared to the control. The axial length $\mathbf{C}$. and average eyeball volume D. ratio in the control and hTSP-1-treated retinoblastoma at 30 days after implantation of retinoblastoma cells. Asterisks indicate statistically significant differences between the control and test cells $(* \mathrm{p}<0.05)$. 
retina, TSP-1 null retina fails to recover from the laserinduced injury, resulting in irreversible damage [51]. Moreover, TSP-1 counteracts the increased neuronal excitability and neuronal death induced by TNF $\alpha$. The role of TSP-1 in controlling the balance between excitation and inhibition could facilitate the recovery of normal synaptic activity after injury [52]. Remotely activated ACs promoted the recovery of excitatory input on surviving motor neurons by the up-regulation of TSP-1 expression [53]. Here, using two kinds of co-culture system, our data showed that TSP-1 prolonged retinal neurocyte survival and effectively inhibited the proliferation of WERI-Rb1 cells and Y79 cells. Therefore, TSP-1 might be a potent therapeutic target for suppressing the growth of tumors while protecting normal retina cells.

In summary, this study provided direct biochemical and genetic evidence supporting the notion that TSP-1 is silenced by histone demethylation in retinoblastoma cells. Moreover, TSP-1 could significantly inhibit cell growth of RB cells. Moreover, the expression level of $\gamma-\mathrm{H} 2 \mathrm{AX}$ and P21, well-characterized in situ markers of DNA DSBs, was significantly decreased in RB cells. DNA NHEJ pathway in WERI-Rb1 cells is significantly inhibited by TSP-1 too. Therefore, our results revealed that TSP-1 is not only a potential target gene in the treatment of retinoblastoma but also a mechanism of TSP-1-mediated anti-retinoblastoma effects. Thus, these findings warrant future clinical investigations of the suppression of retinoblastoma and neuroprotection with TSP-1 during retinal irradiation in the pediatric population.

\section{MATERIALS AND METHODS}

\section{Ethics statement (animals)}

The animals used in this study were obtained from the Center of Experimental Animals of Sun Yat-sen University. The animal experimental procedures were performed in accordance with the ARVO Statement for the Use of Animals in Ophthalmic and Vision Research and was approved and monitored by the Institutional Animal Care and Use Committee of Zhongshan Ophthalmic Center (Permit Number: SYXK (YUE) 2014-007).

\section{Cell culture and tissue sample}

(A) Human retinoblastoma cells, the WERI-Rb1 cell line (ATCC, Manassas, VA, USA), the Y79 cells (ATCC, Manassas, VA, USA), human colorectal carcinoma cells and the RKO cell line (ATCC, Manassas, VA, USA), were cultured in Dulbecco's modified Eagle's medium (DMEM, Gibco, CA, USA) supplemented with 10\% fetal bovine serum (FBS; Gibco, CA, USA) and 1\% penicillin/ streptomycin (Gibco, CA, USA) in a humidified 5\% $\mathrm{CO}_{2}$ incubator. The cells used for the assays were in the exponential growth phase. Trichostatin A (TSA) was obtained from Sigma-Aldrich Corp (Saint Louise,
Missouri). hTSP-1 was purchased from R\&D Systems (Minneapolis, MN, USA). (B) Primary mice retinal neurocytes were cultured as described previously [33]. It has been provided by the animal center of Zhongshan Ophthalmic Center, Sun Yat-sen University, China (C) Coculture system cells were cultured in a transwell system (0.4- $\mu \mathrm{M}$ pore size; BD Bioscience, Bedford, MA, USA) in the presence or absence of 25 nM hTSP-1 for 4 days, respectively.

Fresh tissue samples (retinoblastoma) from patients, after diagnosis and verification by oncologists, were obtained from Zhongshan Ophthalmic Center, Sun Yatsen University. All the patients included in this study required enucleation treatment because of the massive retinoblastoma classified as Group E or some eyes with advanced Group D according to the IIRC (the International Intraocular Retinoblastoma Classification). The samples were collected after a signed consent form was obtained from the patients or their parents/guardians. The present study was approved and monitored by the Institutional Animal Care and Use Committee of Zhongshan Ophthalmic Center, and it adhered to the provisions of the Declaration of Helsinki for research involving human subjects.

\section{Cell viability assayed by CCK-8}

The viability of WERI-Rb1 and Y79 cells and mice retinal neurocytes was assessed by a Cell counting Kit- 8 (CCK8) assay (Dojindo, Japan). The CCK8 reagent was added to each well and cells were incubated for $2 \mathrm{~h}$ at $37^{\circ} \mathrm{C}$. The absorbance (optical density) at $450 \mathrm{~nm}$ was measured. Cell viability was determined by the optical density ratio of a treated culture over an untreated control and represented by quantile normalization in $\log 2$ scale.

\section{Real-time RT-PCR}

The total RNA of cells or tissues was isolated using TRIzol Reagent (Invitrogen, Carlsbad, CA). Reverse transcription-polymerase chain reaction (RT-PCR) assays were performed according to the manufacturer's protocol for the SYBR Prime Script TM RT-PCR Kit (Takara, China). Real-time PCR was employed to measure the expression of TSP-1 using the Roche 480 system (Roche, USA). Relative target gene expression was quantitated according to the comparative $\Delta \mathrm{CT}$ method, i.e., normalized to an endogenous control gene, $\beta$-actin, and relative to a calibrator after calculating the efficiency coefficient: relative expression $=$ $2-\Delta \mathrm{CT}$, where $\Delta \mathrm{CT}=\mathrm{CT}$ (target gene)-CT ( $\beta$-actin). The results are presented as the inverse of the normalized $\mathrm{Ct}$ value (InvCt) or as the relative fold change compared with an unstimulated control. The following primer pairs were used: for TSP-1, 5'- AAGAGCATCACCCTGTTTGTG -3' (sense) and 5'- TCTTCTGGTGTGGTTCCAAAG -3' (antisense); for HDAC4, 5'-GGTTTGAGAGCAGGCAGAAC-3' (sense) and 5'- CAGAGAATGAGGCCAAGGAG -3' (antisense); for 
HDAC8, 5'- CAATGATGCTGTCCTGGGAAT -3' (sense) and 5'- GGAGAATTTGTGCAGGGACAC - 3 ' (antisense); for $\beta$-actin, 5'-CACCACACCTTCTACAATGAG-3' (sense) and 5'- GGAGAATTTGTGCAGGGACAC -3' (antisense).

\section{Western blot analysis}

Cells or tissues were lysed with radioimmunoprecipitation assay buffer. Western blotting was carried out by standard protocols. The following primary antibodies were used: mouse anti-TSP-1 (Abcam, Cambridge, MA); rabbit anti-HDAC4 (Signalway Antibody, Pearland, TX); rabbit anti-GAPDH, rabbit anti-P21, rabbit anti-HDAC8 (Proteintech Group, Chicago, IL); rabbit anti-acetylated histone $\mathrm{H} 3$, rabbit anti-acetylated histone H3 (Lys14, 27, 56 and K18), rabbit anti-phospho-H2AX ser-139 (Cell Signaling Technology, Danvers, MA), synaptophysin (Abcam, Cambridge, MA, USA). Proteins were visualized with horseradish peroxidase (HRP)-conjugated anti-rabbit, antimouse IgG, (Cell Signaling Technology, Danvers, MA) followed by use of the ECL chemiluminescence system. Western blot data was subjected to densitometry analysis by computerized image analysis and software (Gel-Pro Analyzer software ver.6.0, Media Cyberetics, USA).

\section{Plasmid construction}

The NHEJ reporter plasmid pEPI-NHEJ, used as a substrate for the quantitative NHEJ assay, was derived from pEPI-EGFP (generously provided by Dr. H.J. Lipps), which contains a human scaffold/matrix-attached region (S/MAR) and allows for sustained episomal replication without chromosomal integration in human cells [35]. A 52-bp fragment containing an ISceI recognition site and chromosomally integrated GFP-based reporter was inserted into the unique NheI site of plasmid pEPI-EGFP. The HR reporter plasmid pEPI-HR, used as a substrate for the quantitative HR assay, was derived from pEPI-EGFP and pDRGFP [30] (purchased from Addgene, USA). The S/MAR fragment was obtained from pEPI-EGFP by restriction digestion with BgIII and EcorI. The HR fragment was obtained by restriction digestion with SppI and AgeI. Then two fragments were ligated with T4 Ligase. The mitotic stability of the episomal plasmid was determined by quantifying the copy number of the episomal plasmid using real time PCR analysis of extrachromosomal plasmid extracted up to 35 days after transfection.

The plasmid pEPI-GFP-Rb1 was derived from pEPI-GFP [35], which human Rb1 cDNA was inserted in pEPI-GFP by restrictional digested sites, KpnI and BamHI.

\section{TSP-1 promoter-reporter assay}

In each transfection, $2 \times 10^{6}$ WERI-Rb1 cellsor Y79 cells were electroporated with $10 \mu \mathrm{g}$ of $-2033 /+750$ human TSP-1 promoter CAT (Addgene, USA). The cells were harvested and assayed after $24 \mathrm{~h}$. At twenty-four hours after transfected cells were maintained in complete RPMI medium, CAT assays (Roche, Indianapolis, IN, USA) were performed according to the manufacturer's instructions.

\section{Immunohistofluorescence assay}

WERI-Rb1 cells, Y79 cells or tissue sections were fixed in methanol and then were characterized by staining with mouse anti-TSP-1 (Abcam, Cambridge, MA, USA) [54], synaptophysin (Abcam, Cambridge, MA, USA and rabbit anti-phospho-H2AX ser-139 (Cell Signaling Technology, Danvers, MA), respectively. Secondary antimouse antibodies (CST, Lenexa, KS, USA) were added at room temperature, and the nuclei were stained with DAPI. The cells were counterstained with the fluorescent nuclearbinding label 4,6-diamidino-2-phenylindole. Images were obtained by fluorescence microscopy.

\section{Quantitative NHEJ and HR assay}

Seven days after transfection of pEPI-NHEJ or pEPIHR into WERI-Rb1 cells or Y79 cells by electroporation, the cells were treated with hTSP-1 and scrambled controls. At twenty-four hours after treatment, pRFP-ISceI-GR (purchased from Addgene, USA) was transfected into the cells. To allow for ISceI expression and NHEJ or HR, the cells were grown in full medium. If NHEJ or HR occurred, the normal expression of GFP could be observed. The intact pEGFP-N1 was used as the positive control, and treatment with PBS and no plasmid was used as the negative control. Forty-eight hours later, the cells were harvested and subjected to two-color fluorescence analysis. The green fluorescent cells represented the efficiency of NHEJ and HR. For each analysis, 200,000 cells were processed.

\section{Cell cycle assay}

WERI-Rb1 cells or Y79 cells were harvested, fixed with $75 \%$ ice-cold ethanol in PBS and kept at $4^{\circ} \mathrm{C}$. Prior to analysis, cells were washed twice with PBS and then incubated for $30 \mathrm{~min}$ in a propidium iodide staining solution containing $0.05 \mathrm{mg} / \mathrm{ml}$ propidium iodide, $1 \mathrm{mM}$ ethylene-diaminetetraacetic acid (EDTA), 0.1\% Triton $\mathrm{X}-100^{\mathrm{TM}}$ and $1 \mathrm{mg} / \mathrm{ml}$ ribonuclease A (RNase A) (all from Sigma-Aldrich, St. Louis, Missouri). The staining fluorescence intensity was measured using a cytomics FC500 MCL flow cytometer (Beckman Coulter Inc, USA) and used to determine the G1/M ratio.

\section{Assessment of apoptosis}

WERI-Rb1 cells or Y79 cells were harvested and then stained with Annexin V and PI using fluorescein isothiocyanate (FITC)-labeled Annexin V and PI (Annexin-V-PI Kit, Roche, Germany) according to the manufacturer's protocols. Apoptosis was quantified 
by flow cytometry. A minimum of 10,000 events were collected and analyzed using a FACS Calibur instrument and CellQuest Pro software (Becton Dickinson, USA).

\section{Murine xenograft model of retinoblastoma}

The experimental procedures were approved through the Ethical Committee of Sun Yat-sen University (2014007). Swiss background nu/nu mice were obtained from the Center of Experimental Animals of Sun Yat-sen University and were kept in a conventional environment in cages with filter tops. The WERI-Rb1 cells were re-suspended as a single-cell suspension in PBS. Using a Hamilton needle, $2 \times 10^{5}$ WERI-Rb1 cells were injected into the vitreous space of the right eyes of nude mice under sterile conditions using a dissecting microscope; the left eyes were used as untreated controls. The mice were observed weekly for tumor development. Two weeks after cell implantation, the nude mice were randomized (6 mice for each group) to a treatment group receiving vitreous injections two times per week of $2 \mu \mathrm{l}$ of hTSP- 1 at a dose of $2 \mu \mathrm{M}$ or to a control groups receiving balanced salt solution. All of the animals underwent serial ophthalmologic examinations. At day 30 after Weri-Rb1 cell implantation, the globes were enucleated rand fixed in 4\% paraformaldehyde for $12 \mathrm{~h}$. They were then were processed into paraffin-embedded sections, and sequential meridian sections ( $5 \mu \mathrm{m}$ thick) were creating through the optic disc. The sections were stained with H\&E (hematoxylin and eosin).

\section{Statistical analysis}

The data shown are representative of three independent experiments with each experiment performed in triplicate. The data are expressed as the means \pm SDs. Statistical analyses were performed using the SPSS for Windows software package, version 10.5 (Chicago, IL, USA). The differences between mean values were evaluated using Student's two-tailed t-test (for two groups) or analysis of variance (ANOVA, for more than two groups). A P-value $<0.05$ was considered to indicate a statistically significant difference.

\section{ACKNOWLEDGMENTS}

We thank Dr. H.J. Lipps (Institute of Cell Biology, University Witten/Herdecke, Witten, Germany) for their kind contribution of materials used in this study, and Dr. MS. Zeng (Collaborative Innovation Center of Cancer Medicine, Sun Yat-sen University) for excellent suggestion.

\section{CONFLICTS OF INTEREST}

There are no actual or potential conflicts of interest, including any financial, personal, or other relationships with people or organizations that could inappropriately influence the current study.

\section{GRANT SUPPORT}

This work was supported by the grant from the National Natural Science Foundation (Project: 81170850).

\section{Authors' contributions}

Conception and design: K. Yu, J. Zhuang

Development of methodology: P. Chen, N. Yu, Z. Zhang, Y. Yang, N. Wu, L Xu, J Zhang, M. Liang, K Li, J. Zhuang

Acquisition of data (provided animals, acquired and managed patients, provided facilities, etc.): N. Yu, Z. Zhang, P. Chen, Y. Yang, N. Wu, L Xu, J Zhang, M. Liang, K Li, J. Zhuang

Analysis and interpretation of data (e.g., statistical analysis, biostatistics, computational analysis): P. Chen, N. Yu, Z. Zhang, K. Yu, J. Zhuang

Writing, review, and/or revision of the manuscript: P. Chen, N. Yu, Z. Zhang, K. Yu, J. Zhuang

Administrative, technical, or material support (i.e., reporting or organizing data, constructing databases): P. Zhang, M. Liang, K Li

Study supervision: K. Yu, J. Zhuang.

\section{REFERENCES}

1. Dimaras H, Kimani K, Dimba EA, Gronsdahl P, White A, Chan HS, Gallie BL. Retinoblastoma. Lancet. 2012; 379: 14364-6.

2. Errico A. Cancer therapy: retinoblastoma--chemotherapy increases the risk of secondary cancer. Nat Rev Clin Oncol. 2014; $11: 623$.

3. Sid B, Sartelet H, Bellon G, EI Btaouri H, Rath G, Delorme N, Haye B, Martiny L. Thrombospondin 1: a multifunctional protein implicated in the regulation of tumor growth. Crit Rev Oncol Hematol. 2004; 49: 245-58.

4. Gutierrez LS. The role of thrombospondin 1 on intestinal inflammation and carcinogenesis. Biomark Insights. 2008; 3: 171-8.

5. Sheibani N, Frazier WA. Thrombospondin 1 expression in transformed endothelial cells restores a normal phenotype and suppresses their tumorigenesis. Proc Natl Acad Sci USA. 1995; 92: 6788-92.

6. Nucera C, Porrello A, Antonello ZA, Mekel M, Nehs MA, Giordano TJ, Gerald D, Benjamin LE, Priolo C, Puxeddu E, Finn S, Jarzab B, Hodin RA, et al. B-Raf (V600E) and thrombospondin-1 promote thyroid cancer progression. Proc Natl Acad Sci U S A. 2010; 107: 10649-54.

7. Tokunaga T, Nakamura M, Oshika Y, Tsuchida T, Kazuno M, Fukushima Y. Alterations in tumour suppressor gene p53 correlate with inhibition of thrombospondin-1 gene 
expression in colon cancer cells. Virchows Arch. 1998; 433: 415-8.

8. Michaud M, Poyet P. Control of the expression of thrombospondin 1 in human breast cancer cell lines. Anticancer Res. 1994; 14: 1127-31.

9. Tenan M, Fulci G, Albertoni M, Diserens AC, Hamou MF, El Atifi-Borel M. Thrombospondin-1 is downregulated by anoxia and suppresses tumorigenicity of human glioblastoma cells. J Exp Med. 2000; 191: 1789-98.

10. Yang QW, Liu S, Tian Y, Salwen HR, Chlenski A, Weinstein J, Cohn SL. Methylation-associated silencing of the thrombospondin-1 gene in human neuroblastoma. Cancer Res. 2003; 63: 6299-310.

11. Hiscott P, Paraoan L, Choudhary A, Ordonez JL, Al-Khaier A, Armstrong DJ. Thrombospondin 1, thrombospondin 2 and the eye. Prog Retin Eye Res. 2006; 25: 1-18.

12. Firlej V, Mathieu JR, Gilbert C, Lemonnier L, Nakhlé J, Gallou-Kabani C, Guarmit B, Morin A, Prevarskaya N, Delongchamps NB, Cabon F. Thrombospondin-1 Triggers Cell Migration and Development of Advanced Prostate Tumors. Cancer research. 2011; 71: 7649-58.

13. Horiguchi H, Yamagata S, Rong Qian Z, Kagawa S, Sakashita N. Thrombospondin-1 is highly expressed in desmoplastic components of invasive ductal carcinoma of the breast and associated with lymph node metastasis. J Med Invest. 2013; 60: 91-96.

14. Borsotti P, Ghilardi C, Ostano P, Silini A, Dossi R, Pinessi D, Foglieni C, Scatolini M, Lacal PM, Ferrari R, Moscatelli D, Sangalli F, D'Atri S, et al. Thrombospondin-1 is part of a Slug-independent motility and metastatic program in cutaneous melanoma, in association with VEGFR-1 and FGF-2. Pigment Cell Melanoma Res. Pigment Cell Melanoma Res. 2015; 28: 73-81.

15. Seliger C, Leukel P, Moeckel S, Jachnik B, Lottaz C, Kreutz M, Brawanski A, Proescholdt M, Bogdahn U, Bosserhoff AK, Vollmann-Zwerenz A, Hau P, et al. Lactate-modulated induction of THBS-1 activates transforming growth factor (TGF)-beta2 and migration of glioma cells in vitro. PLoS One. 2013; 8: e78935.

16. Byrne GJ, Hayden KE, McDowell G, Lang H, Kirwan CC, Tetlow L, Kumar S, Bundred NJ. Angiogenic characteristics of circulating and tumoural thrombospondin-1 in breast cancer. Int J Oncol. 2007; 31: 1127-32.

17. Rusnati M, Urbinati C, Bonifacio S, Presta M, Taraboletti G. Thrombospondin-1 as a Paradigm for the Development of Antiangiogenic Agents Endowed with Multiple Mechanisms of Action. Pharmaceuticals. 2010; 3: 1241-78.

18. Li K, Yang M, Yuen PM, Chik KW, Li CK, Shing MM, Lam HK, Fok TF. Thrombospondin-1 induces apoptosis in primary leukemia and cell lines mediated by CD36 and Caspase-3. Int J Mol Med. 2003; 12: 995-1001.

19. Tsuchida R, Osawa T, Wang F, Nishii R, Das B, Tsuchida S, Muramatsu M, Takahashi $T$, Inoue $\mathrm{T}$,
Wada Y, Minami T, Yuasa Y, Shibuya M. BMP4/ Thrombospondin-1 loop paracrinically inhibits tumor angiogenesis and suppresses the growth of solid tumors. Oncogene. 2014; 33: 3803-11.

20. Yao M, Rogers NM, Csányi G, Rodriguez AI, Ross MA, St Croix C, Knupp H, Novelli EM, Thomson AW, Pagano PJ, Isenberg JS. Thrombospondin-1 activation of signal-regulatory protein- $\alpha$ stimulates reactive oxygen species production and promotes renal ischemia reperfusion injury. J Am Soc Nephrol. 2014; 25:1171-86.

21. Isenberg JS, Maxhimer JB, Hyodo F, Pendrak ML, Ridnour LA, DeGraff WG, Tsokos M, Wink DA, Roberts DD. Thrombospondin-1 and CD47 limit cell and tissue survival of radiation injury. Am J Pathol. 2008; 173:1100-12.

22. Guo N, Krutzsch HC, Inman JK, Roberts DD. Thrombospondin 1 and type I repeat peptides of thrombospondin 1 specifically induce apoptosis of endothelial cells. Cancer Res. 1997; 57: 1735-42.

23. John W Lawler, inventor; Beth Israel Deaconess Medical Center, Inc., assignee. Thrombospondin-1 type 1 repeat polypeptides. United States patent US 7223731. 2007 May 29.

24. Lu Z, Kipnis J. Thrombospondin 1--a key astrocyte-derived neurogenic factor. ASEB J. 2010; 24: 1925-34.

25. Blake SM, Strasser V, Andrade N, Duit S, Hofbauer R, Schneider WJ, Nimpf J. Thrombospondin-1 binds to ApoER2 and VLDL receptor and functions in postnatal neuronal migration. EMBO J. 2008; 27: 3069-80.

26. Christopherson KS, Ullian EM, Stokes CC, Mullowney CE, Hell JW, Agah A, Lawler J, Mosher DF, Bornstein P, Barres BA. Thrombospondins are astrocyte-secreted proteins that promote CNS synaptogenesis. Cell. 2005; 20: 421-33.

27. Lu Z, Kipnis J. Thrombospondin 1--a key astrocyte-derived neurogenic factor. FASEB J. 2010; 24: 1925-34.

28. Léveillé F, Papadia S, Fricker M, Bell KF, Soriano FX, Martel MA, Puddifoot C, Habel M, Wyllie DJ, Ikonomidou C, Tolkovsky AM, Hardingham GE. Suppression of the intrinsic apoptosis pathway by synaptic activity. J Neurosci. 2010; 30: 2623-35.

29. Liauw J, Hoang S, Choi M, Eroglu C, Choi M, Sun GH, Percy M, Wildman-Tobriner B, Bliss T, Guzman RG, Barres BA, Steinberg GK. Thrombospondins 1 and 2 are necessary for synaptic plasticity and functional recovery after stroke. J Cereb Blood Flow Metab. 2008; 28: 1722-32.

30. Yu KM, Ge J, Summers JB, Li F, Liu X, Ma P, Kaminski J, Zhuang J. TSP-1 secreted by bone marrow stromal cells contributes to retinal ganglion cell neurite outgrowth survival. PLoS ONE. 2008; 3: e2470.

31. Lindner DJ, Wu Y, Haney R, Jacobs BS, Fruehauf JP, Tuthill R, Borden EC. Thrombospondin-1 expression in melanoma is blocked by methylation and targeted reversal by 5-Aza-deoxycytidine suppresses angiogenesis. Matrix Biol. 2013; 32: 123-32. 
32. Zhuang J, Jiang G, Willers H, Xia F. Exonuclease function of human Mre11 promotes deletional nonhomologous end joining. J Biol Chem. 2009; 284: 30565-73.

33. Koike M, Yutoku Y, Koike A. Accumulation of p21 proteins at DNA damage sites independent of p53 and core NHEJ factors following irradiation. Biochem Biophys Res Commun. 2011; 412: 39-43.

34. Yamauchi M, Imajoh-Ohmi S, Shibuya M. Novel antiangiogenic pathway of thrombospondin-1 mediated by suppression of the cell cycle. Cancer Science. 2007; 98: 1491-97.

35. Zhuang J, Zhang J, Willers H, Wang H, Chung JH, van Gent DC, Hallahan DE, Powell SN, Xia F. Checkpoint kinase 2-mediated phosphorylation of BRCA1 regulates the fidelity of nonhomologous end-joining. Cancer Res. 2006; 66: 1401-8.

36. Pierce AJ, Johnson RD, Thompson LH, Jasin M. XRCC3 promotes homology-directed repair of DNA damage in mammalian cells. Genes Dev. 1999; 13: 2633-8.

37. Schulte-Uentrop L, EI-Awady RA, Schliecker L, Willers $\mathrm{H}$, Dahm-Daphi J. Distinct roles of XRCC4 and Ku80 in non-homologous end-joining of endonuclease- and ionizing radiation-induced DNA double-strand breaks. Nucleic Acids Res. 2008; 36: 2561-9.

38. Willers H, Husson J, Lee LW, Hubbe P, Gazemeier F, Powell SN, Dahm-Daphi J. Distinct mechanisms of nonhomologous end joining in the repair of site-directed chromosomal breaks with noncomplementary and complementary ends. Radiat Res. 2006; 166: 567-74.

39. Chen P, Hu H, Chen Z, Cai XX, Zhang Z, Yang Y, Yu N, Zhang J, Xia L, Ge J, Yu KM, Zhuang J. BRCA1 Silencing Is Associated with Failure of DNA Repairing in Retinal Neurocytes. PLoS One. 2014; 9: e99371.

40. Yang Y, Tian SJ, Brown B, Chen P, Hu H, Xia L, Zhang J, Cai XX, Chen Z, Pan XK, Ge J, Yu KM, Zhuang J. The Rb1 gene inhibits the viability of retinoblastoma cells by regulating homologous recombination. Int $\mathrm{J}$ Mol Med. 2013; 32: 137-43.

41. Jenke AC, Stehle IM, Herrmann F, Eisenberger T, Baiker A, Bode J, Fackelmayer FO, Lipps HJ. Nuclear scaffold/matrix attached region modules linked to a transcription unit are sufficient for replication and maintenance of a mammalian episome. Proc Natl Acad Sci U S A. 2004; 101: 11322-7.

42. Li Q, Ahuja N, Burger PC, Issa JP. Methylation and silencing of the Thrombospondin-1 promoter in human cancer. Oncogene. 1999; 18: 3284-9.

43. Wang S, Mahesh SP, Liu J, Geist C, Zderic V. Focused ultrasound facilitated thermo-chemotherapy for targeted retinoblastoma treatment: a modeling study. Exp Eye Res. 2012; 100: 17-25.
44. Pham CT, Blanc R, Lumbroso-Le Rouic L, Pistocchi S, Bartolini B, Piotin M. Access to the ophthalmic artery by retrograde approach through the posterior communicating artery for intra-arterial chemotherapy of retinoblastoma. Neuroradiology. 2012; 54: 845-8.

45. Takahashi K, Mernaugh RL, Friedman DB, Weller R, Tsuboi N, Yamashita H, Quaranta V, Takahashi T. Thrombospondin-1 acts as a ligand for CD148 tyrosine phosphatase. Proc Natl Acad Sci U S A. 2012; 109: 1985-90.

46. Stevaux O, Dyson NJ. A revised picture of the E2F transcriptional network and RB function. Curr Opin Cell Biol. 2002; 14: 684-91.

47. Watnick RS, Rodriguez RK, Wang S, Blois AL, Rangarajan A, Ince T, Weinberg RA. Thrombospondin-1 repression is mediated via distinct mechanisms in fibroblasts and epithelial cells. Oncogene. 2014; 34: 2823-35.

48. Kaur S, Soto-Pantoja DR, Stein EV, Liu C, Elkahloun AG, Pendrak ML, Nicolae A, Singh SP, Nie Z, Levens D, Isenberg JS, Roberts DD. Thrombospondin-1 signaling through CD47 inhibits self-renewal by regulating c-Myc and other stem cell transcription factors. Sci Rep. 2013; $3: 1673$.

49. Crawford DC, Jiang X, Taylor A, Mennerick S. Astrocytederived thrombospondins mediate the development of hippocampal presynaptic plasticity in vitro. J Neurosci. 2012; 32: $13100-10$.

50. Nakamura R, Nakamoto C, Obama H, Durward E, Nakamoto M. Structure-function analysis of Nel, a thrombospondin-1-like glycoprotein involved in neural development and functions. J Biol Chem. 2012; 287: 3282-91.

51. Ng TF, Turpie B, Masli S. Thrombospondin-1-mediated regulation of microglia activation after retinal injury. Invest Ophthalmol Vis Sci. 2009; 50: 5472-8.

52. Hennekinne L, Colasse S, Triller A, Renner M. Differential control of thrombospondin over synaptic glycine and AMPA receptors in spinal cord neurons. J Neurosci. 2013; 33: 11432-9.

53. Tyzack GE, Sitnikov S, Barson D, Adams-Carr KL, Lau NK, Kwok JC, Zhao C, Franklin RJ, Karadottir RT, Fawcett JW, Lakatos A. Astrocyte response to motor neuron injury promotes structural synaptic plasticity via STAT3-regulated TSP-1 expression. Nat Commun. 2014; 5: 4294.

54. Bhutto IA, Uno K, Merges C, Zhang L, McLeod DS, Lutty GA. Reduction of endogenous angiogenesis inhibitors in Bruch's membrane of the submacular region in eyes with age-related macular degeneration. Arch Ophthalmol. 2008; 126: $670-8$. 